\title{
Energy Efficiency Measurement and Decomposition in China's Land Transportation with Excluding Non-Management Factors
}

\author{
Chengzhen Xu, Shixiong Wang* \\ School of Economics and Management, Zhejiang Sci-Tech University, Hangzhou Zhejiang, China
}

Received: 23 June 2020

Accepted: 21 October 2020

\begin{abstract}
With the rapid development of industrialization in China, the demand for transportation service has increased substantially, causing huge energy consumption in transport sector. The land transportation (including railway transportation and highway transportation) is the most important source of energy consumption in China. In this study, the parallel Slack-Based Measure (SBM) model and three-stage of Data Envelopment Analysis (DEA) approach are combined to measure the energy efficiency of land transportation system and two subsystems from 2013 to 2017 with excluding the non-management factors. The empirical results lead to four conclusions: (a) non-management factors do exert unfavorable influence on the energy efficiency measurement, ignoring which will overestimate the efficiency value. (b) There exist significant area disparities in energy efficiencies of the land transportation and its two subsystems. (c) The energy efficiencies of the whole land transportation and the highway transportation present a significant upward trend, while the changing trend is not promising for the railway transportation. (d) The railway transportation has a greater impact on the efficiency of the whole system in 2013 and 2014, which has weakened in the next three years.
\end{abstract}

Keywords: energy efficiency measurement, efficiency decomposition, non-management factors, parallel SBM model, three-stage DEA model

\section{Introduction}

Since the reform and opening-up policy adopted in 1978, China's economy has achieved great development. Compared with 1978, gross domestic product (GDP) in 2017 increased by nearly 224 times. Meanwhile, with the rapid development of urbanization and industrialization in China, the demand for transportation service has

*e-mail: sxwang@zstu.edu.cn increased a lot. In accordance with the data released by the Ministry of Transport of the People's Republic of China (MTPRC) in 2018, the converted turnover of transport sector reached 21253.9 billion ton-kilometers in 2017, an increase of $15.2 \%$ over 2013. The huge demand has resulted in more infrastructure investment and energy consumption in transport sector [1].

The land transportation, which consists of railway transportation and highway transportation, has been the most important sector within the whole transport system [2]. In line with the data issued by NBSC 
(National Bureau of Statistics of China), the passenger turnover and freight turnover of land transportation reached 17.7 billion people and 40.6 billion tons in 2017, accounting for $95.5 \%$ and $84.4 \%$ of the whole transport sector. Based on the above statistical data, it can be observed that it is more meaningful to concentrate on the land transportation rather that other sectors in the whole transport system. In addition, as one of the three high-energy-consumption sectors in China, the transportation sector faced a serious challenge of resource utilization [3], according to the data of China Statistical Yearbook, the energy consumption of China's transportation sector is 421.91 million tons of standard coal in 2017, accounting for $9.41 \%$ of China's final energy consumption, and the land transportation constitutes more than $80 \%$ of energy consumption in the whole transportation sector. And, the energy consumption in China's land transportation is dominated by fuel energy, which results in severe environmental pollution problems. Although the renewable energy strategies have been emphasized by the government in recent years, the energy consumption structure cannot be changed recently [4]. To achieve the sustainable development, it's essential to reduce the energy consumption in China's land transportation. The improvement of energy efficiency is regarded as the most efficient methods to decrease energy consumption [5-6]. Hence, measuring the energy efficiency of the land transportation is important. Based on this thought, this paper wants to discuss the following question. Has the energy efficiency of the whole land transportation been improved in recent years? How about the efficiency of the railway transportation and the highway transportation? To address the above issues, this paper combines the parallel slack-based measure (SBM) model and three-stage data envelopment analysis (DEA) method to investigate the energy efficiency of China's land transportation.

\section{Literature Review}

The issues about energy efficiency have attracted extensive attention of scholars, generally speaking, there are two types indicators that are used to measure the energy efficiency, named single factor energy efficiency and total factor energy efficiency [7], respectively. The former indicator is not reasonable whilst computing the energy efficiency, because the energy is selected as the only input index without taking into account the contributions of other production elements like labor and capital. Thus, most researches on energy efficiency measurement utilize the later concept which not only consider the energy input but also other key factors. Following the work of $\mathrm{Hu}$ and Wang [7], numerous empirical analysis about energy efficiency have been done by many methods, mainly including parametric and non-parametric approaches. For example, Lin and Wang [8] applied stochastic frontier analysis (SFA) approach to analyze energy efficiency of China's iron and steel sectors. Recently, applying SFA method, Xie et al. [9] calculates the provincial energy efficiency and energy saving potential of China's transport sector. Also, much energy efficiency analysis has been finished on the basis of data envelopment analysis (DEA), a widely used non-parametric approach which is firstly introduced by Charnes et al. [10]. Since DEA can solve the multiple inputs and multiple outputs without considering the relationship between variables [11], DEA has been extensively used to evaluate the efficiency in many areas, such as health care [12-13], industry sectors [14-15], banks [16-17]. The existing research articles on the total-factor energy efficiency evaluation can be mainly divided into two categories. The first category applies the extended DEA methods to measure single process efficiency. The second category uses the network DEA methods to study the two-stage efficiency of production system.

Many researches have been done on the evaluation of single process energy efficiency by applying radial and non-radial measures. For instance, Wang et al. [18] measured the energy efficiency of 35 sub-industrial sectors in Beijing via improved Bootstrap-DEA model. Based on a DEA-Tobit analysis, Borozan [19] assessed the energy efficiency of European Regions and explore the factors affecting the efficiency scores. Recently, applying the game cross-efficiency DEA, Yang and Wei [20] measured the urban total factor energy efficiency in China. However, radial measures may ignore the slack variables, leading to overestimate the efficiency [21], So, non-radial approach is widely applied in empirical research [22]. For example, Song et al. [23] combined the window DEA with the super-efficiency SBM model to compute the energy consumption and environmental performance of highway transportation system in China. Liu et al. [24] adopted non-radial DEA and window analysis to measure energy-environment efficiency of road and railway sectors of 30 provinces in China. Applying super efficiency SBM model, Yang et al. [25] investigated the energy efficiency of China's 30 provinces. Another issue that should be mentioned is that environmental factors, statistical noise and administrative inefficiency are considered as three important elements that exert impacts on the efficiency evaluation [26-27]. To obtain the real efficiency which is only affected by administrative inefficiency, environmental factors and statistical noise, which are collectively named as non-management factors for convenience, have to be eliminated. To approach this concern, Fried et al. [28] proposed three-stage DEA model which can exclude the impacts of nonmanagement factors. Since then, the three-stage DEA has widely been used in energy efficiency measurement. For example, Cui and Li [1] applied a three-stage virtual DEA model to evaluate transportation efficiencies. Chen et al. [29] and Wang et al. [30] employed the three-stage DEA model to analyze the provincial energy efficiency in China. 
However, these models, whether radial or non-radial, always treat the production system as a "black box" without considering the internal divisions. However, actual production activities are not independent, such as land transportation which consists of railway and highway transportation, ignoring the internal process will not explore the disparities of energy efficiency of the two subsystems. Thus, the results obtained may be misleading without considering the intermediate procedures [31]. To address this problem, Färe and Grosskopf [32] introduced a network DEA model that can open the "black box". In application, a number of studies have focused on considering the internal structure of production system [33-34]. Following these studies, three most commonly used types of network structures have been developed, called as parallel structure [35-36], series structure [37-39] and mixed structure [40-41], respectively. There are several papers about energy efficiency measurement of transport sector by using the network DEA approach. For instance, $\mathrm{Wu}$ et al. [42] and Lei et al. [43] applied a parallel DEA approach to measure the energy and environmental performance of transportation systems in China with a network structure consisting of passenger and freight transportation. Liu et al. [2] employed a parallel SBM measure to evaluate the environmental efficiency of China's land transportation which includes railway and highway transportation. $\mathrm{Xu}$ and Cui [44] applied Network Epsilon-based Measure and Network SBM to assess the overall energy efficiency and divisional efficiency of 19 international airlines.

An unavoidable problem derived from the network DEA method is to explore the relationship between the system and the subsystem efficiencies. In general, efficiency aggregation and efficiency decomposition are always used to discuss the relations. The efficiency aggregation method firstly defines the relationships, based on which the system and subsystem efficiencies can be measured with multiplicative or additive form. For the multiplicative form, the system efficiency is defined as the product of the subsystem efficiencies [37, 45], while a weighted average of subsystem efficiencies for the additive form [36, 38, 46]. Nevertheless, efficiency aggregation can't reveal the real relationship between the whole system and subsystem efficiencies, due to that the whole system efficiency is not evaluated independently of subsystem efficiencies. In contrast, the efficiency decomposition approach evaluates the system efficiency by directly using all inputs and outputs of the whole production activities [47], and then obtains the relationships between system and subsystem efficiencies. Many studies have been done on efficiency decomposition, regrettably, most of them are based on the radial methods, such as Kao [48], Tang et al. [49] and $\mathrm{Wu}$ et al. [50]. Non-radial means are less used in efficiency decomposition due to its complexity, and according to Kao [47], those studies based on nonradial approaches that claimed to be a decomposition of system efficiency are actually aggregations of division efficiencies. Until recently, Kao [51] propose an efficiency decomposition method based on non-radial measures.

By reviewing the literature, it's observed that few studies focus on energy efficiency evaluation of land transportation and the measurement of energy efficiency in transport sector always neglects the impacts of non-management factors. However, the land transportation system is a parallel structure, thus, both the internal process and non-management factors should be considered. In this paper, parallel SBM model and three-stage DEA method are combined to measure the energy efficiency of China's land transportation with excluding the non-management factors. And then, the energy efficiencies of railway and highway transportation are also calculated by means of efficiency decomposition approach.

\section{Materials and Methods}

\section{Parallel System and Methodological Framework}

Prior studies always treated the transportation system as an entirety. However, the real land transportation system is composed of railway transportation and highway transportation. According to Kao [52], a production system can be considered in a parallel structure, if all processes can operate independently. In this sense, the land transportation of each province is a parallel system and two modes of transportation (railway and highway transportations) are two parallel subsystems. The inefficiency of the two subsystems can be easily found with this decomposition. Therefore, decision makers can take proper measures to enhance the efficiency of the whole system. Fig. 1 shows the parallel structure, for these two subsystems, the railway and highway length, labor and energy consumption are used to generate desirable outputs (passenger turnover and freight turnover). The indicators will be described in detail in the following section.

Depending on the parallel structure of the land transportation, an extended parallel network SBM model, introduced by Kao [51], will be adopted to measure the energy efficiency of land transportation in China. There are two main reasons for selecting the parallel SBM model in this paper. First, this selected model is non-radial, which could construct the efficiency indicator by directly introducing the slacks of inputs and outputs, thereby making it have higher discrimination power than radial approaches [5354]. Second, traditional network SBM models define the system efficiency according to a predetermined relationship with the subsystem efficiencies [47]. However, this method cannot reveal the real relationship between system and subsystem efficiencies [55]. In contrast, the parallel SBM model of this paper measures the system efficiency from the inputs it consumes and the outputs it produces, and then derives the relationship 


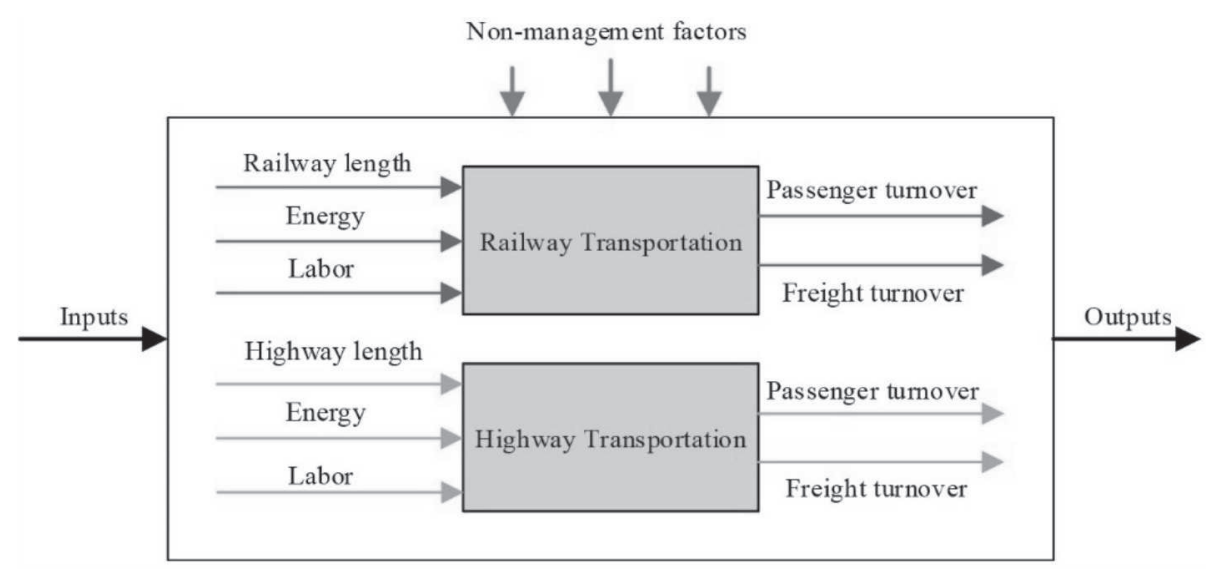

Fig. 1. The parallel structure of the land transportation.

via efficiency decomposition. With this relationship, the subsystems that result in the inefficiency of the system can be identified. Then, the efficiency of the system can be effectively increased by making improvements in these subsystems.

Moreover, considering that the non-management factors may affect the efficiency measurement, which may make the results distorted. This paper will apply the SFA approach to eliminate the non-management factors. The methodological framework is represented in Fig. 2. At the first stage, the energy efficiency of the land transportation in each province under the influences of non-management factors are measured via the parallel SBM model. In the second phase, the slack term of each input sequence is disintegrated into two sequences, including non-management factors and administrative inefficiency, and then the initial input variables will be adjusted by excluding the non-management factors based on the SFA method. At the third phase, the energy efficiencies of land transportation will be reevaluated with the adjusted inputs and initial outputs via the parallel SBM model. Meanwhile, the energy efficiencies

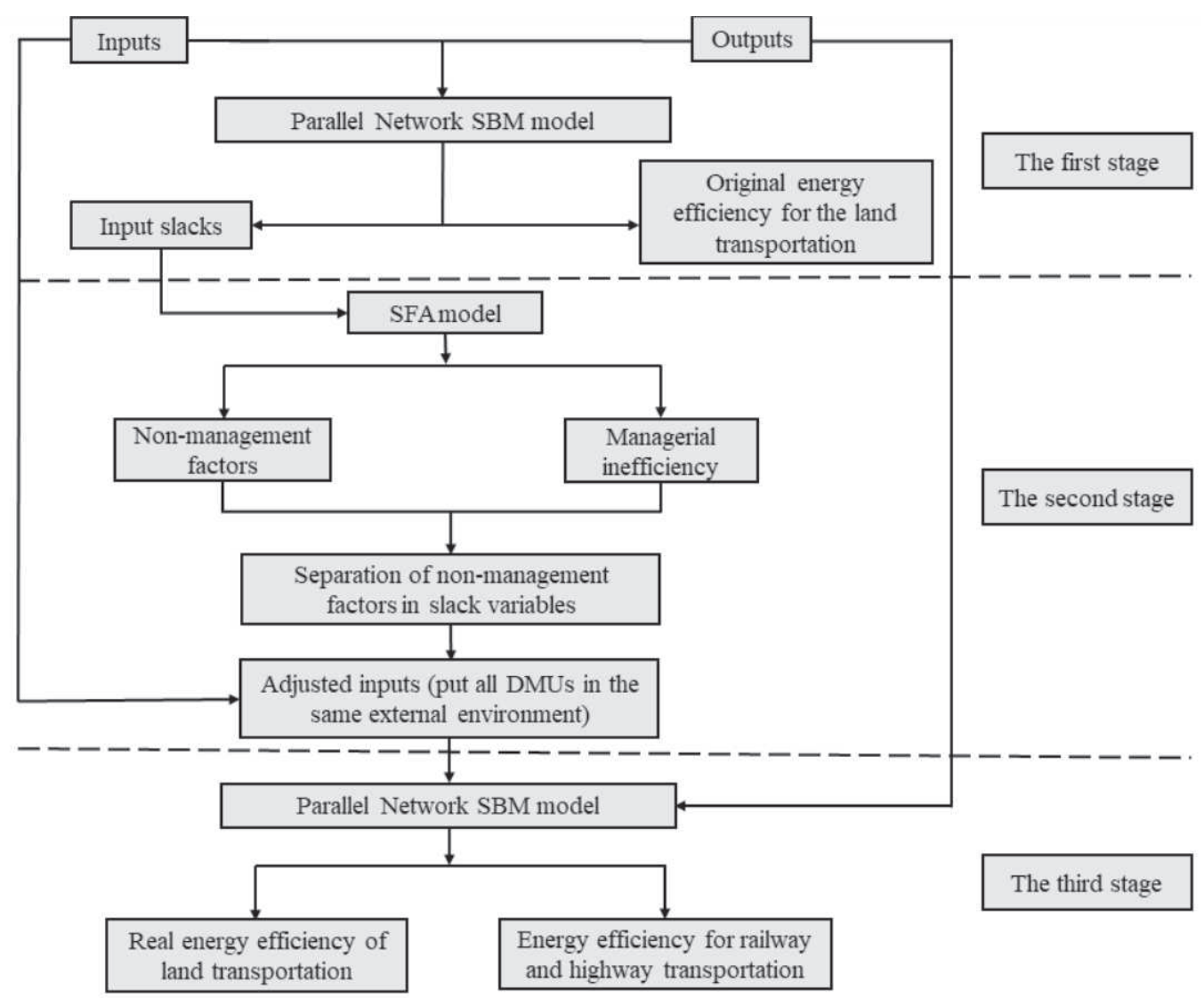

Fig. 2. Methodological framework for China's provincial energy efficiency evaluation. 
of railway and highway transportation will be computed by means of efficiency decomposition approach.

\section{First Stage}

\section{Parallel SBM Model}

In this stage, the parallel SBM model is employed to measure the energy efficiencies of land transportation of China's 30 provincial-level provinces without considering non-management factors, each DMU corresponds to a province in the analysis.

Assume that there are $k$ DMUs with $m$ inputs and $s$ outputs of the whole land transportation. With regard to each subsector, $x_{i j}{ }^{1}=\left(i=1,2, \ldots m_{1}\right)$ and $y_{i j}{ }^{1}=\left(r=1,2, \ldots s_{1}\right)$ denote the input index and output index of railway transportation, respectively; while $x_{i j}{ }^{2}=\left(i=1,2, \ldots m_{2}\right)$ and $y_{i j}{ }^{2}=\left(r=1,2, \ldots s_{2}\right)$ represent the input and output vector of highway transportation, respectively. It's apparent that $m=m_{1}+m_{2}, s=s_{1}+s_{2}$.

Note that railway and highway transportation are operating independently in the whole system. So, the SBM model for measuring the efficiency of land transportation under variable returns to scale can be represented as follows:

$$
\begin{gathered}
\min \rho^{S}=\frac{1-\frac{1}{m_{1}+m_{2}}\left(\sum_{i=1}^{m_{1}} \frac{s_{i}^{1-}}{x_{i 0}^{1}}+\sum_{i=1}^{m_{2}} \frac{s_{i}^{2-}}{x_{i 0}^{2}}\right)}{1+\frac{1}{s_{1}+s_{2}}\left(\sum_{r=1}^{s_{1}} \frac{s_{r}^{1+}}{y_{r 0}^{1}}+\sum_{r=1}^{s_{2}} \frac{s_{r}^{2+}}{y_{r 0}^{2}}\right)} \\
\operatorname{s.t.}\left\{\begin{array}{l}
\sum_{j=1}^{k} x_{i j}^{1} u_{j}+s_{i}^{1-}=x_{i 0}^{1}, i=1,2, \ldots, m_{1} ; \\
\sum_{j=1}^{k} y_{r j}^{1} u_{j}-s_{r}^{1+}=y_{r 0}^{1}, r=1,2, \ldots, s_{1} ; \\
\sum_{j=1}^{k} v_{j}+s_{i}^{2-}=x_{i 0}^{2}, i=1,2, \ldots, m_{2} ; \\
\sum_{j=1}^{k} y_{r j}^{2} v_{j}-s_{r}^{2+}=y_{r 0}^{2}, r=1,2, \ldots, s_{2} ; \\
\sum_{j=1}^{k} u_{j}=1, \sum_{j=1}^{k} v_{j}=1 ; \\
u_{j}, v_{j}, s_{i}^{1-}, s_{i}^{2-}, s_{r}^{1+}, s_{r}^{2+} \geq 0, j=1, \ldots, k .
\end{array}\right.
\end{gathered}
$$

...where $\rho^{\mathrm{S}}$ denotes the energy efficiency of the province being evaluated, $s_{i}^{1-}$ and $s_{r}{ }^{1+}$ are respectively the slacks of inputs and outputs of railway transportation, the same as $s_{i}^{2-}$ and $s_{r}^{2+}, u_{j}$ and $v_{j}$ implies the weight vector of DMU. Let $\lambda_{j}=\theta u_{j}, S_{i}^{1-}=\theta s_{i}{ }^{1-}, S_{r}{ }^{1+}=\theta s_{r}{ }^{1+}, \gamma_{j}=\theta v_{j}$, $S_{i}^{2-}=\theta s_{i}^{2-}, S_{r}^{2+}=\theta s_{r}{ }^{2+}$ based on the Charnes-Cooper transformation, model (1) can be transformed into the following linear model (2):

$$
\min \rho^{S}=\theta-\frac{1}{m_{1}+m_{2}}\left(\sum_{i=1}^{m_{1}} \frac{S_{i}^{1-}}{x_{i 0}^{1}}+\sum_{i=1}^{m_{2}} \frac{S_{i}^{2-}}{x_{i 0}^{2}}\right)
$$$$
s . t .\left\{\begin{array}{l}
\sum_{j=1}^{k} x_{i j}^{1} \lambda_{j}+S_{i}^{1-}=\theta x_{i 0}^{1}, i=1,2, \ldots, m_{1} ; \\
\sum_{j=1}^{k} y_{r j}^{1} \lambda_{j}-S_{r}^{1+}=\theta y_{r 0}^{1}, r=1,2, \ldots, s_{1} ; \\
\sum_{j=1}^{k} \lambda_{j}=\theta ; \\
\sum_{j=1}^{k} x_{i j}^{2} \gamma_{j}+S_{i}^{2-}=\theta x_{i 0}^{2}, i=1,2, \ldots, m_{2} ; \\
\sum_{j=1}^{k} \gamma_{j}-S_{r}^{2+}=\theta y_{r 0}^{2}, r=1,2, \ldots, S_{2} ; \\
\theta+\frac{1}{s_{1}+S_{2}}\left(\sum_{r=1}^{s_{1}} \frac{S_{r}^{1+}}{y_{r 0}^{1}}+\sum_{r=1}^{s_{2}} \frac{S_{r}^{2+}}{y_{r 0}^{2}}\right)=1 ; \\
\lambda_{j}, \gamma_{j}, \theta, S_{i}^{1-}, S_{i}^{2-}, S_{r}^{1+}, S_{r}^{2+} \geq 0, j=1, \ldots, k .
\end{array}\right.
$$

Based on model (2), the energy efficiencies of China's land transportation can be obtained without taking into account the non-management factors. And, it should be pointed out that if and only if $\rho^{\mathrm{S}}=1$, the province being evaluated will be considered efficient.

\section{Second Stage}

\section{Similar SFA Model}

The energy efficiency of every DMU that ignores non-management factors can be computed at the first phase. Meanwhile, the slack variable of each input can also be obtained, which reflect the gaps between the actual and targeted input values. The slack variable of input $z_{n j}$ is represented by $S_{n j}$, which is influenced by non-management factors and managerial inefficiency. For each input slack variable, the SFA regression function can be constructed as follows:

$$
\begin{gathered}
S_{n j}=f^{n}\left(z_{j} ; \beta^{n}\right)+v_{n j}+\mu_{n j}, n=1,2, \ldots, m, \\
j=1,2, \ldots, k
\end{gathered}
$$

...where $z_{j}=\left(z_{1 j}, z_{2 j}, \ldots, z_{h j}\right)$ represents the environmental variable influencing the energy efficiency of province $j ; \beta^{n}$ is the coefficient of the environment variable, representing the parameter to be evaluated; $f^{n}\left(z_{j} ; \beta^{n}\right)=z_{j} \beta^{n}$ indicates the effect of environmental factors on $S_{n j} ; v_{n j}+\mu_{n j}$ refers to the mixed error, where $v_{n j}$ is the random noise component of input $n$ for province $j$, and $v_{n j} \sim N\left(0, \sigma_{v}^{2}\right), \mu_{n j}$ represents the managerial inefficiency term of input $n$ for province $j$, and $\mu_{n j} \sim N^{+}\left(u, \sigma_{u}{ }^{2}\right)$. 
Set $\gamma=\sigma_{v}^{2} /\left(\sigma_{v}^{2}+\sigma_{u}^{2}\right)$,while the value of $\gamma$ near 1 means that the impacts of managerial inefficiency dominate the energy efficiency of land transportation, and it's reasonable to apply SFA for estimation. On the contrary, the value of $\gamma$ close to 0 indicates that the energy inefficiency is mainly influenced by nonmanagement factors, so ordinary least squares (OLS) is more appropriate than SFA approach.

Further, in order to adjust all DMUs in the same exterior condition, the non-management factors that exert an influence on energy efficiency evaluation should be eliminated by the following formula:

$$
\begin{gathered}
X_{n j}^{A}=X_{n j}+\left[\max \left\{z_{j}, \hat{\beta}^{n}\right\}-z_{j} \hat{\beta}\right]^{n}+\left[\max \left\{\hat{v}_{n j}\right\}-\hat{v}_{n j}\right], \\
n=1,2, \ldots, m, j=1,2, \ldots, k
\end{gathered}
$$

$X_{n j}^{A}$ and $X_{n j}$ in Equation (2) represent the adjusted input and original input of province $j$, respectively. The term $\left[\max \left\{z_{j}, \hat{\beta}^{n}\right\}-z_{j} \hat{\beta}^{n}\right]$ is used to adjust the external environmental factors, while $\left[\max \left\{\hat{v}_{n j}\right\}-\hat{v}_{n j}\right]$ is applied to make all DMUs at the same luck level.

\section{Third Stage}

\section{Revised Parallel SBM Model}

The adjusted values of input variables calculated at the second stage and the original output values used at the first phase are brought into the parallel SBM model again, Then, the actual energy efficiency of China's land transportation excluding the impacts of nonmanagement factors can be obtained.

\section{Energy Efficiency Decomposition}

The efficiency calculated above can only reflect the energy utilization of the land transportation. Accordingly, in order to measure the energy efficiency of these two subsystems and analyze the real relationships between the whole system and the subsystems efficiencies, the efficiency decomposition method is applied based on the work of Kao [51], the calculation formulas can be written as follows:

$$
\begin{gathered}
\rho^{f}=\frac{1-\frac{1}{m_{f}} \sum_{i=1}^{m_{f}} \frac{s_{i}^{f-}}{x_{i 0}^{f}}}{1+\frac{1}{s_{f}} \sum_{r=1}^{s_{f}} \frac{s_{r}^{f+}}{y_{r 0}^{f}}}, f=1,2 . \\
\omega^{f}=\frac{m_{f}}{m_{1}+m_{2}} \times \frac{1+\frac{1}{s_{f}} \sum_{r=1}^{s_{f}} \frac{s_{r}^{f+}}{y_{r 0}^{f}}}{1+\frac{1}{s_{1}+s_{2}}\left(\sum_{r=1}^{s_{1}} \frac{s_{r}^{1+}}{y_{r 0}^{1}}+\sum_{r=1}^{s_{2}} \frac{s_{r}^{2+}}{y_{r 0}^{2}}\right)}, f=1,2 .
\end{gathered}
$$

...where $\rho^{f}$ denotes the energy efficiency of subsystem $f$, and term $w^{f}$ is the weight coefficient of subsystem $f$, the other parameters have the same meaning as above. Based on Fig. 1, it can be found that $m_{1}=m_{2}$, and $s_{1}=s_{2}$. Thus, $w^{1} \rho^{1}+w^{2} \rho^{2}=\rho^{S}$ and $w^{1}+w^{2}=1$ can be proved. Apparently, the system efficiency is a linear combination of the subsystem efficiencies.

\section{Variables and Data}

\section{Input and Output Indices}

The SBM model is constructed in accordance with the input and output variables in terms of DMUs, the DMUs in this study refer to China's thirty PARs (provincial administrative provinces), which will be called collectively as provinces. Owing to lack of data, Taiwan, Hong Kong, Tibet and Macau are excluded. Following the pervious researches [56-57], labor for railway and highway transportation, railway and highway length, energy consumption of railway and highway transportation are also selected as input index in this paper. Among these indicators, labor input is expressed by the number of employees at the end of year in railway and highway transportation; railway and highway length denote the total length of railway and highway routes; In general, diesel and gasoline consumption mainly come from highway transportation, so these two indicators can be selected as measurements of the energy consumption of highway transportation since gasoline and diesel are two of the largest types of energy consumed. The main energy consumption of railway transportation is electricity and diesel, but the diesel consumption of the highway transportation is far greater than that of the railway transportation and it is difficult to separate the diesel consumption from the two sectors, therefore, this paper chooses electricity consumption as the energy consumption of railway transportation because the electricity consumption in land transportation mainly come from railway transportation. It's noted that fuel and electricity consumption will be converted to the standard coal equivalent (SCE). The output indices used for land transportation are railway/highway passenger turnover and railway/highway freight turnover [58-59], i.e. the product of distance and weight of railway/highway transportation, which can reflect the number of services provided by railway and highway transportation [60]. The input and output indices in this article are presented in Table 1. The labor for railway and highway transportation, the railway and highway length, the passenger and freight turnover are derived from China Statistical Yearbook (2014-2018), the energy consumption of railway and transportation are collected from China Energy Statistical Yearbook (2014-1018). The statistical descriptions of the collected data of input-output variables are demonstrated in Table 2. 
Table 1. Indices of inputs and outputs.

\begin{tabular}{|c|c|c|c|}
\hline \multicolumn{2}{|c|}{ Land transportation sector } & Indices & Units \\
\hline \multirow{5}{*}{ Railway transportation } & \multirow{3}{*}{ Inputs } & Railway length & 100 kilometers \\
\hline & & Energy & 10 thousands tons of SCE \\
\hline & & Labor & 1000 person \\
\hline & \multirow{2}{*}{ Outputs } & Railway passenger turnover & 100 million passenger kilometers \\
\hline & & Railway freight turnover & 100 million ton kilometers \\
\hline \multirow{5}{*}{ Highway transportation } & \multirow{3}{*}{ Inputs } & Highway length & 100 kilometers \\
\hline & & Energy & 10 thousands tons of SCE \\
\hline & & Labor & 1000 person \\
\hline & \multirow{2}{*}{ Outputs } & Highway passenger turnover & 100 million passenger kilometers \\
\hline & & Highway freight turnover & 100 million ton kilometers \\
\hline
\end{tabular}

Table 2. The statistical descriptions of the collected data of input-output variables.

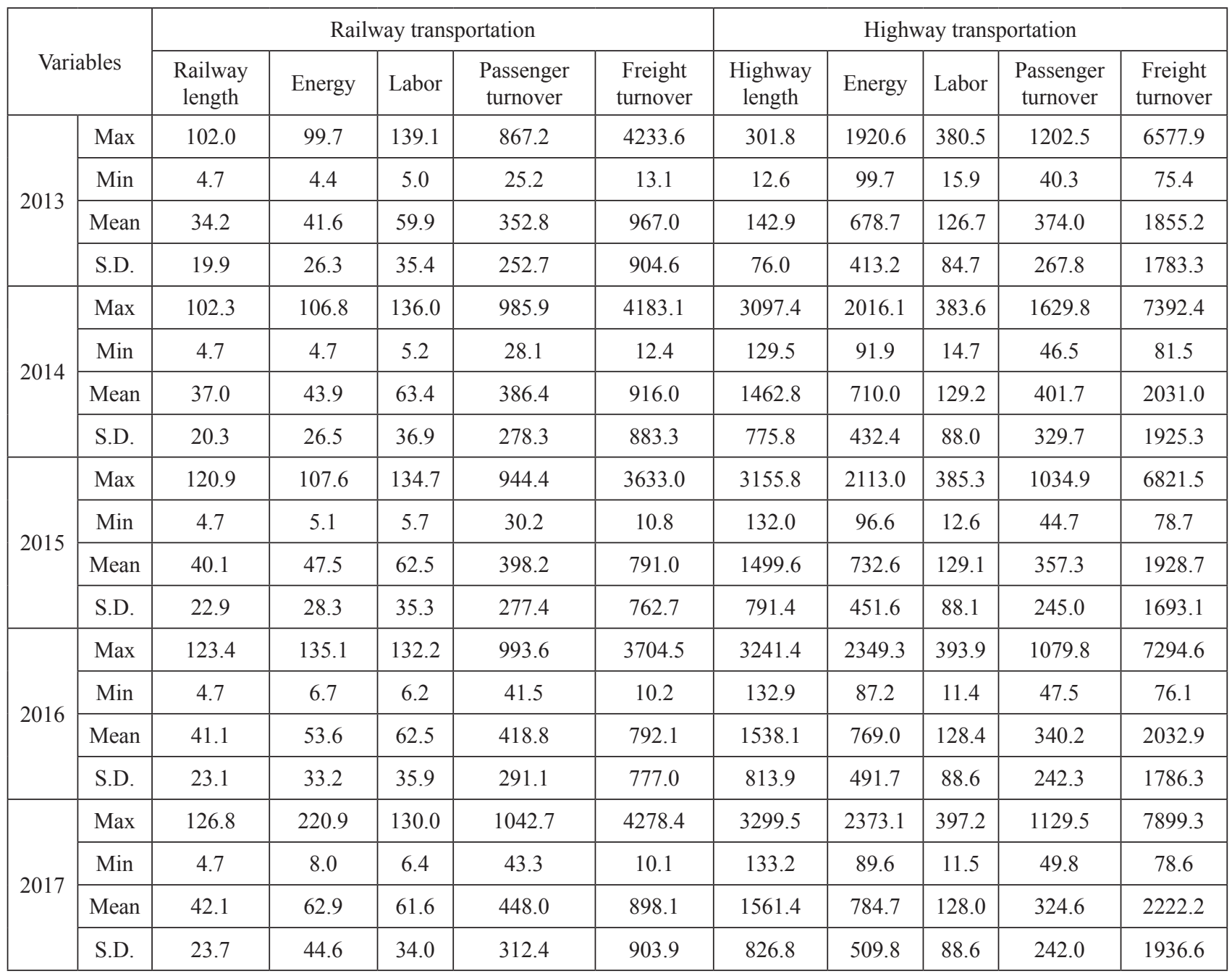

\section{Environmental Variable Indices}

The energy efficiencies of the land transportation are not only affected by inputs and outputs of the whole production system, but also influenced by external factors, such as environmental factors and statistical noise. Following the previous researches [60-61], per capita GDP and industrial structure are selected as exterior environmental factors that have an impact on energy efficiency of land transportation. Per capita 
GDP can reflect the economic disparities between different provinces. Generally speaking, the higher the per capita GDP is, the more demand for transportation services will have, which will result in more energy consumption. Industrial structure is represented by the proportion of the added value of the secondary industry in the GDP of each province. In general, the improvement of industrial structure will increase the freight turnover of industry sector, which will lead to more energy consumption. The data on per capita GDP and industrial structure are collected from China Statistical Yearbook (2014-1018).

Table 3. Energy efficiency of land transportation ignoring non-management factors.

\begin{tabular}{|c|c|c|c|c|c|c|c|}
\hline Area & Province/Year & 2013 & 2014 & 2015 & 2016 & 2017 & Mean \\
\hline \multirow{12}{*}{$\begin{array}{l}\text { Eastern } \\
\text { area }\end{array}$} & Beijing & 1.0000 & 1.0000 & 1.0000 & 1.0000 & 1.0000 & 1.0000 \\
\hline & Tianjin & 1.0000 & 1.0000 & 1.0000 & 1.0000 & 1.0000 & 1.0000 \\
\hline & Hebei & 1.0000 & 1.0000 & 1.0000 & 1.0000 & 1.0000 & 1.0000 \\
\hline & Liaoning & 0.5146 & 0.4967 & 0.5300 & 0.5565 & 0.5499 & 0.5295 \\
\hline & Shanghai & 1.0000 & 1.0000 & 1.0000 & 1.0000 & 1.0000 & 1.0000 \\
\hline & Jiangsu & 1.0000 & 0.6106 & 1.0000 & 1.0000 & 0.9625 & 0.9146 \\
\hline & Zhejiang & 0.7227 & 0.5572 & 0.7936 & 0.8065 & 0.8338 & 0.7427 \\
\hline & Fujian & 0.2389 & 0.2321 & 0.2620 & 0.2665 & 0.2464 & 0.2492 \\
\hline & Shandong & 0.4853 & 0.4351 & 0.6618 & 0.5774 & 0.5407 & 0.5400 \\
\hline & Guangdong & 1.0000 & 0.3205 & 0.4949 & 0.4501 & 0.4639 & 0.5459 \\
\hline & Hainan & 1.0000 & 1.0000 & 1.0000 & 1.0000 & 1.0000 & 1.0000 \\
\hline & Mean & 0.8147 & 0.6956 & 0.7947 & 0.7870 & 0.7816 & 0.7747 \\
\hline \multirow{9}{*}{$\begin{array}{c}\text { Central } \\
\text { area }\end{array}$} & Shanxi & 0.3234 & 0.2860 & 0.3804 & 0.3842 & 0.3780 & 0.3504 \\
\hline & Jilin & 0.4568 & 0.4448 & 0.5137 & 0.5232 & 0.5054 & 0.4888 \\
\hline & Anhui & 1.0000 & 1.0000 & 1.0000 & 1.0000 & 0.9412 & 0.9882 \\
\hline & Jiangxi & 0.6960 & 0.6981 & 0.8274 & 0.8730 & 0.8594 & 0.7908 \\
\hline & Henan & 0.7322 & 0.6504 & 0.8790 & 0.8143 & 1.0000 & 0.8152 \\
\hline & Hubei & 0.4270 & 0.4450 & 0.6123 & 0.6124 & 0.6175 & 0.5428 \\
\hline & Hunan & 1.0000 & 1.0000 & 1.0000 & 1.0000 & 1.0000 & 1.0000 \\
\hline & Heilongjiang & 0.4358 & 0.4339 & 0.5564 & 0.4555 & 0.4664 & 0.4696 \\
\hline & Mean & 0.6339 & 0.6198 & 0.7211 & 0.7078 & 0.7210 & 0.6807 \\
\hline \multirow{13}{*}{$\begin{array}{c}\text { Western } \\
\text { area }\end{array}$} & Guangxi & 0.5718 & 0.5335 & 0.7599 & 0.7725 & 0.7207 & 0.6717 \\
\hline & Inner Mongolia & 0.5379 & 0.5446 & 0.7278 & 0.7675 & 0.7368 & 0.6629 \\
\hline & Chongqing & 0.2535 & 0.2582 & 0.3214 & 0.3328 & 0.3031 & 0.2938 \\
\hline & Sichuan & 0.6461 & 0.6368 & 0.6462 & 0.4767 & 0.3974 & 0.5606 \\
\hline & Guizhou & 0.7915 & 0.7386 & 0.7726 & 0.7431 & 0.6990 & 0.7490 \\
\hline & Yunnan & 0.2908 & 0.2618 & 0.3599 & 0.3481 & 0.3602 & 0.3241 \\
\hline & Shaanxi & 0.4410 & 0.4382 & 0.5499 & 0.5911 & 0.5852 & 0.5211 \\
\hline & Gansu & 0.4949 & 0.4920 & 0.6359 & 0.7938 & 0.6577 & 0.6149 \\
\hline & Qinghai & 1.0000 & 1.0000 & 1.0000 & 0.6218 & 0.6201 & 0.8484 \\
\hline & Ningxia & 1.0000 & 1.0000 & 1.0000 & 1.0000 & 1.0000 & 1.0000 \\
\hline & Xinjiang & 0.3699 & 0.3212 & 0.3857 & 0.4155 & 0.3741 & 0.3733 \\
\hline & Mean & 0.5816 & 0.5659 & 0.6508 & 0.6239 & 0.5867 & 0.6018 \\
\hline & Average value & 0.6810 & 0.6278 & 0.7224 & 0.7061 & 0.6940 & 0.6863 \\
\hline
\end{tabular}




\section{Empirical Results}

\section{Empirical Results of Parallel SBM in the First Stage}

The energy efficiency of the land transportation from 2013 to 2017 calculated by the parallel SBM model are listed in Table 3. As shown in Table 3, first, average energy efficiency of land transportation in 2013-2017 is $0.6810,0.6278,0.7224,0.7061,0.6940$, respectively, which implies that the energy efficiency is not very high and need to be increased. Secondly, seven provinces (including Beijing, Tianjin, Hebei, Shanghai, Hainan, Hunan and Ningxia) are superior to other provinces because their average energy efficiencies are equal to 1 , which shows that they are both efficient from 2013 to 2017. Shanxi, Chongqing, Yunnan and Xinjiang behave worse than other provinces, with their average energy efficiencies of $0.3504,0.2938,0.3241,0.3733$, respectively.

To further analyze the energy efficiency of land transportation at the provincial level, 30 provinces are divided into three groups (Eastern area, Central area, and Western area) based on geography. These groups are listed in Table 4. It can be found that the average energy efficiency of the eastern, central and western area in $2013-2017$ is $0.7747,0.6807,0.6018$, respectively, presenting obvious ladder-like distribution with the east having the highest efficiency value, followed by the central, and then the west. The results show that regional disparities exist in energy efficiency of China's land transportation.

Some deviations maybe exist between the above analysis results and actual situation due to the neglect of non-management factors. Therefore, the SFA regression will be used to eliminate non-management factors and adjust the initial input index.

\section{Results of SFA Regression Analysis in the Second Stage}

In this phase, the slack variable of each input from first stage is regarded as explained variables, with per capita GDP and industrial structure selected as explanatory variables. SFA regression is constructed by using Frontier 4.1. Here, taking the results in 2017 as an example, the SFA estimation results is demonstrated in Table 5. It can be seen that the LR test value of six slack variables all pass the critical value of the single side generalized likelihood ratio test, and are all under $1 \%$ significance level, which indicates that it's reasonable to construct SFA regression. The value of $\gamma$ for six regression model are all near 1 and pass $1 \%$ significance test, which shows the variation of the total slacks of inputs are dominated by managerial inefficiency.

Most of regression coefficients listed in Table 5 have passed the $1 \%$ significance test, which indicates that the external environment factors do exert effects on the energy efficiency measurement of the land transportation. Thus, it is necessary to eliminate the impact of external environmental factors. In addition, it should be noted that different coefficients represent different relationships between input slacks and environmental variables. Concretely, positive regression coefficient means the increase of environmental variables will lead to the increase of input slack variables and reduce the energy efficiency while the negative regression coefficient demonstrates the favorable influence brought by environmental variables on the increase on energy efficiency.

For the per capita GDP, the coefficients are negative for the railway/highway length and labor for railway, but positive for the rest. They are significant for railway length and energy for highway on $10 \%$ level, and are significant for the remaining inputs on $1 \%$ level, indicating that the raising of per capita GDP will decrease the input slacks of labor for railway and railway/highway length while simultaneously increasing the input slacks of energy consumption of land transportation and labor for highway which will hinder the improvement of energy efficiency. The reason may be the excessive investment in the transport sector over the past several years, which led to the reconstruction and unreasonable competition [62]. Thus, the performance of land transportation resource utilization should be further improved to increase the energy efficiency.

For the industrial structure, the coefficients are all significant at the level of $1 \%$ and negative for the railway/highway length, but positive for the rest. This result means, with the improvement of industrial structure, the increase of the demand for transportation service will negatively influence the slacks of railway and highway length while positively affecting the slacks of energy consumption and labor for land transportation, which would have a negative impact on the energy efficiency of land transportation. However, with the implementation of energy saving

Table 4. Regional division based on geography.

\begin{tabular}{|c|c|}
\hline Areas & Provinces \\
\hline Eastern area (11 provinces) & $\begin{array}{c}\text { Beijing, Tianjin, Hebei, Liaoning, Shanghai, Jiangsu, Zhejiang, Fujian, Shandong, Guangdong, } \\
\text { Hainan }\end{array}$ \\
\hline Central area (8 provinces) & Shanxi, Jilin, Anhui, Jiangxi, Hanan, Hubei, Hunan, Heilongjiang \\
\hline Western area (11 provinces) & $\begin{array}{c}\text { Guangxi, Inner Mongolia, Chongqing, Sichuan, Guizhou, Yunnan, Shaanxi, Gansu, Qinghai, } \\
\text { Ningxia, Xinjiang }\end{array}$ \\
\hline
\end{tabular}


Table 5. The results of SFA analysis.

\begin{tabular}{|c|c|c|c|c|c|c|}
\hline $\begin{array}{l}\text { Explanatory } \\
\text { variable }\end{array}$ & $\begin{array}{l}\text { Railway } \\
\text { length }\end{array}$ & $\begin{array}{l}\text { Energy for } \\
\text { Railway }\end{array}$ & $\begin{array}{l}\text { Labor for } \\
\text { Railway }\end{array}$ & $\begin{array}{l}\text { Highway } \\
\text { length }\end{array}$ & $\begin{array}{l}\text { Energy for } \\
\text { Highway }\end{array}$ & $\begin{array}{l}\text { Labor for } \\
\text { Highway }\end{array}$ \\
\hline Constant value & $\begin{array}{c}3.9 \mathrm{E}+02 * * * \\
(3.9 \mathrm{E}+02)\end{array}$ & $\begin{array}{c}-6.7 \mathrm{E}+00 * * * \\
(-9.29)\end{array}$ & $\begin{array}{c}-1.4 \mathrm{E}+04 * * * \\
(1.4 \mathrm{E}+04)\end{array}$ & $\begin{array}{c}3.1 \mathrm{E}+04 * * * \\
(2.0 \mathrm{E}+03)\end{array}$ & $\begin{array}{c}-2.6 \mathrm{E}+02 * * * \\
(-2.6 \mathrm{E}+02)\end{array}$ & $\begin{array}{c}-3.9 \mathrm{E}+04 * * * \\
(-3.9 \mathrm{E}+04)\end{array}$ \\
\hline Per capita GDP & $\begin{array}{l}-4.8 \mathrm{E}-03 * \\
(-1.4 \mathrm{E}+00)\end{array}$ & $\begin{array}{l}2.8 \mathrm{E}-05^{* * *} \\
(9.26 \mathrm{E}+00)\end{array}$ & $\begin{array}{c}-2.1 \mathrm{E}-01 * * * \\
(-2.8 \mathrm{E}+01)\end{array}$ & $\begin{array}{c}-2.8 \mathrm{E}-01^{* * *} \\
(-5.6 \mathrm{E}+00)\end{array}$ & $\begin{array}{c}1.0 \mathrm{E}-03^{*} \\
(1.5 \mathrm{E}+00)\end{array}$ & $\begin{array}{l}1.1 \mathrm{E}-01 * * * \\
(2.9 \mathrm{E}+00)\end{array}$ \\
\hline $\begin{array}{l}\text { Industrial } \\
\text { structure }\end{array}$ & $\begin{array}{c}-7.4 \mathrm{E}+02 * * * \\
(-7.4 \mathrm{E}+02)\end{array}$ & $\begin{array}{l}8.2 \mathrm{E}+00 * * * \\
(9.32 \mathrm{E}+00)\end{array}$ & $\begin{array}{c}4.5 \mathrm{E}+04 * * * \\
(4.5 \mathrm{E}+04)\end{array}$ & $\begin{array}{c}-5.5 \mathrm{E}+04 * * * \\
(-4.2 \mathrm{E}+04)\end{array}$ & $\begin{array}{c}3.3 \mathrm{E}+02 * * * \\
(3.3 \mathrm{E}+02)\end{array}$ & $\begin{array}{c}5.9 \mathrm{E}+04 * * * \\
(5.9 \mathrm{E}+04)\end{array}$ \\
\hline Sigma-squared & $\begin{array}{c}1.7 \mathrm{E}+06^{* * *} \\
(1.7 \mathrm{E}+06)\end{array}$ & $\begin{array}{c}3.6 \mathrm{E}+01 * * * \\
(3.7 \mathrm{E}+01)\end{array}$ & $\begin{array}{c}1.3 \mathrm{E}+09^{* * *} \\
1.3(\mathrm{E}+09)\end{array}$ & $\begin{array}{c}1.4 \mathrm{E}+09^{* * *} \\
(1.4 \mathrm{E}+09)\end{array}$ & $\begin{array}{c}9.7 \mathrm{E}+04 * * * \\
(9.7 \mathrm{E}+04)\end{array}$ & $\begin{array}{c}7.4 \mathrm{E}+08 * * * \\
(7.4 \mathrm{E}+08)\end{array}$ \\
\hline$\gamma$ & $\begin{array}{c}1.0 \mathrm{E}+00^{* * *} \\
(4.6 \mathrm{E}+04)\end{array}$ & $\begin{array}{c}1.0 \mathrm{E}+00 * * * \\
(1.9 \mathrm{E}+07)\end{array}$ & $\begin{array}{l}1.0 \mathrm{E}+00^{* * *} \\
(1.18 \mathrm{E}+03)\end{array}$ & $\begin{array}{c}9.9 \mathrm{E}-01 * * * \\
(8.1 \mathrm{E}+01)\end{array}$ & $\begin{array}{c}1.0 \mathrm{E}+00^{* * *} \\
(7.5 \mathrm{E}+04)\end{array}$ & $\begin{array}{c}1.0 \mathrm{E}+00^{* * *} \\
(3.8 \mathrm{E}+04)\end{array}$ \\
\hline Log likelihood & -232.2 & -70.0 & -335.5 & -338.6 & -190.0 & -324.8 \\
\hline LR test & 23.7 & 27.0 & 14.7 & 11.8 & 23.0 & 20.4 \\
\hline
\end{tabular}

Note: * indicates the $10 \%$ significance level, *** indicates the $1 \%$ significance level. Data in brackets demonstrate t-statistics of the coefficients

policy, the adjustments of industrial structure will contribute to the change of China's industrial sector from high-energy-consumption to low-energyconsumption sector $[6,63]$. As results, the unfavorable impacts of industrial structure on energy efficiency will be under control.

Results Following an Adjustment of Input Variables in the Third Stage

The energy efficiency of China's land transportation from 2013 to 2017 is computed again with the adjusted inputs obtained in the second phase and original outputs by applying parallel SBM model. The results are shown in Table 6.

Based on Table 6. First, Hebei, Shanghai, Ningxia and Anhui performed better than other provinces from 2013 to 2017, as the efficiency scores of these four provinces are equal to 1, except for Anhui in 2017. These provinces can be used as a benchmark. And the efficiency of energy utilization of land transportation in China is not very good owing to the low average efficiency values (i.e., 0.6507) during the research period. Second, about 6 regions (including Fujian, Shanxi, Heilongjiang, Chongqing, Yunnan, Xinjiang) did not have good performance from 2013 to 2017, as their average energy efficiency are all less than 0.5 . Taking Yunnan as an example, the energy efficiencies of Yunnan from 2013 to 2017 are 0.2686, 0.2464, 0.3578, $0.3493,0.3554$, respectively, and the average efficiency of Yunnan from 2013 to 2017 is only 0.3155, which is greatly lower than the average efficiency value of 30 provinces. Third, Fig. 3 illustrates the energy efficiency changes over time in 2013, 2015 and 2017. The average efficiency value in 2013 is close to 0.61 , while 0.71 in 2015 and 0.68 in 2017. Comparing the energy efficiency in 2013 and 2015, 15 provinces exhibit a large increase in energy efficiency, accounting for
$50 \%$ of all provinces. Only Guangdong and Tianjin exhibit a sharp decrease in energy efficiency, and the other provinces do not change significantly. While analyzing the energy efficiency of 2015 and 2017, it can be observed that the energy efficiency in 5 provinces (including Beijing, Tianjin, Sichuan, Heilongjiang, Qinghai) significantly changed while the energy efficiencies in remaining provinces changed little.

The average energy efficiencies of three areas from 2013 to 2017 are shown in Fig. 4. First, the energy efficiencies of eastern and central area are higher than national level except central area in 2014, and it can be inferred that the lessening of national energy efficiency in 2017 mainly derives from the decrease of energy efficiencies in Western area. Therefore, more attention should be paid on Western area in next few years to improve the whole performance of energy utilization. Second, the energy efficiency of eastern area are significantly higher than those of central area and western area, indicating that although the influences brought by non-management factors have been eliminated, the provincial differences still exist in China due to uneven development among three areas. Third, the average energy efficiencies of three areas in land transportation show similar change tendencies from 2014 to 2017. According to Fig. 4, it can be observed that the efficiency values declined in 2014, and rose sharply from 2014 to 2015, with a slight decline in 2016 and did not have obvious fluctuations in 2017. In addition, it should be also noted that the average energy efficiencies of three areas in 2017 have significantly increased compared with 2013.

\section{Decomposition of Provincial Energy Efficiency in Land Transportation}

The efficiencies acquired in the third stage can only reflect the energy efficiency of land transportation in 
Table 6. Energy efficiency of land transportation considering non-management factors.

\begin{tabular}{|c|c|c|c|c|c|c|c|}
\hline Area & Province/Year & 2013 & 2014 & 2015 & 2016 & 2017 & Mean \\
\hline \multirow{12}{*}{ Eastern area } & Beijing & 0.4785 & 0.5142 & 1.0000 & 0.5568 & 0.7666 & 0.6632 \\
\hline & Tianjin & 1.0000 & 0.7773 & 0.5918 & 0.7692 & 1.0000 & 0.8277 \\
\hline & Hebei & 1.0000 & 1.0000 & 1.0000 & 1.0000 & 1.0000 & 1.0000 \\
\hline & Liaoning & 0.5260 & 0.5038 & 0.5386 & 0.5627 & 0.5559 & 0.5374 \\
\hline & Shanghai & 1.0000 & 1.0000 & 1.0000 & 1.0000 & 1.0000 & 1.0000 \\
\hline & Jiangsu & 0.7917 & 0.5820 & 1.0000 & 1.0000 & 0.9293 & 0.8606 \\
\hline & Zhejiang & 0.7170 & 0.5468 & 0.7004 & 0.7483 & 0.8160 & 0.7057 \\
\hline & Fujian & 0.2530 & 0.2395 & 0.2685 & 0.2813 & 0.2479 & 0.2580 \\
\hline & Shandong & 0.4894 & 0.4370 & 0.6471 & 0.5785 & 0.5381 & 0.5380 \\
\hline & Guangdong & 1.0000 & 0.3215 & 0.5115 & 0.4731 & 0.4772 & 0.5566 \\
\hline & Hainan & 0.3779 & 1.0000 & 1.0000 & 1.0000 & 1.0000 & 0.8756 \\
\hline & Mean & 0.6939 & 0.6293 & 0.7507 & 0.7245 & 0.7574 & 0.7112 \\
\hline \multirow{9}{*}{$\begin{array}{c}\text { Central } \\
\text { area }\end{array}$} & Shanxi & 0.3281 & 0.2835 & 0.3840 & 0.3855 & 0.3796 & 0.3521 \\
\hline & Jilin & 0.4837 & 0.4740 & 0.5324 & 0.5509 & 0.5227 & 0.5128 \\
\hline & Anhui & 1.0000 & 1.0000 & 1.0000 & 1.0000 & 0.9443 & 0.9889 \\
\hline & Jiangxi & 0.7009 & 0.7092 & 0.8297 & 0.7915 & 0.8641 & 0.7791 \\
\hline & Henan & 0.7395 & 0.6574 & 0.8765 & 0.8232 & 1.0000 & 0.8193 \\
\hline & Hubei & 0.4259 & 0.4479 & 0.5981 & 0.6113 & 0.6226 & 0.5412 \\
\hline & Hunan & 0.6519 & 0.6502 & 1.0000 & 1.0000 & 1.0000 & 0.8604 \\
\hline & Heilongjiang & 0.3294 & 0.3110 & 0.5335 & 0.4024 & 0.3416 & 0.3836 \\
\hline & Mean & 0.5824 & 0.5667 & 0.7193 & 0.6956 & 0.7094 & 0.6547 \\
\hline \multirow{13}{*}{$\begin{array}{c}\text { Western } \\
\text { area }\end{array}$} & Guangxi & 0.5627 & 0.5329 & 0.7660 & 0.7858 & 0.7180 & 0.6731 \\
\hline & Inner Mongolia & 0.5920 & 0.5782 & 0.7645 & 0.7837 & 0.7484 & 0.6934 \\
\hline & Chongqing & 0.2621 & 0.2561 & 0.3124 & 0.3336 & 0.3030 & 0.2934 \\
\hline & Sichuan & 0.6496 & 0.6389 & 0.6497 & 0.4874 & 0.3913 & 0.5634 \\
\hline & Guizhou & 0.3190 & 0.3534 & 0.7765 & 0.7566 & 0.7079 & 0.5827 \\
\hline & Yunnan & 0.2686 & 0.2464 & 0.3578 & 0.3493 & 0.3554 & 0.3155 \\
\hline & Shaanxi & 0.4591 & 0.4558 & 0.5507 & 0.6073 & 0.6259 & 0.5398 \\
\hline & Gansu & 0.4688 & 0.4340 & 0.5883 & 0.8142 & 0.6161 & 0.5843 \\
\hline & Qinghai & 1.0000 & 1.0000 & 1.0000 & 0.6296 & 0.5984 & 0.8456 \\
\hline & Ningxia & 1.0000 & 1.0000 & 1.0000 & 1.0000 & 1.0000 & 1.0000 \\
\hline & Xinjiang & 0.3522 & 0.3076 & 0.3872 & 0.4198 & 0.3792 & 0.3692 \\
\hline & Mean & 0.5395 & 0.5276 & 0.6503 & 0.6334 & 0.5858 & 0.5873 \\
\hline & Grand mean & 0.6076 & 0.5753 & 0.7055 & 0.6834 & 0.6817 & 0.6507 \\
\hline
\end{tabular}

China without exploring the efficiency gaps between railway and highway transportation. So, formula (5) is applied to calculate the subsystem efficiencies with adjusted inputs. In this subsection, the energy efficiency for railway transportation is represented by "EERT", while the energy efficiency for highway transportation is represented by "EEHT". The calculation results are presented in Table 7.

For the railway transportation, first, 11 provinces (including Beijing, Hebei, Inner Mongolia, Shanghai, Jiangsu, Anhui, Jiangxi, Hunan, Hainan, Qinghai and Ningxia) are on the efficiency frontier from 2013 to 2017, except for Jiangxi in 2016. Two provinces are efficient in three years (Tianjin in 2013, 2016 and 2017; Zhejiang in 2013, 2014 and 2017). Guangdong and Gansu are only efficient in 2013. The provinces with the worst performance are Fujian in 2013, 2015, 2016, 2017 and Guangdong in 2014. Second, the average EERT between 2013 and 2017 is $0.774,0.691,0.701$, $0.699,0.710$, respectively. The EERT is not high and has a downward tendency during the research period, this result means that the performance of energy utilization in China's railway transportation is not very high. Third, Fig. 5a) depicts the change trend of average energy efficiencies of three areas in railway transportation. It can be found that the western area is the worst with 


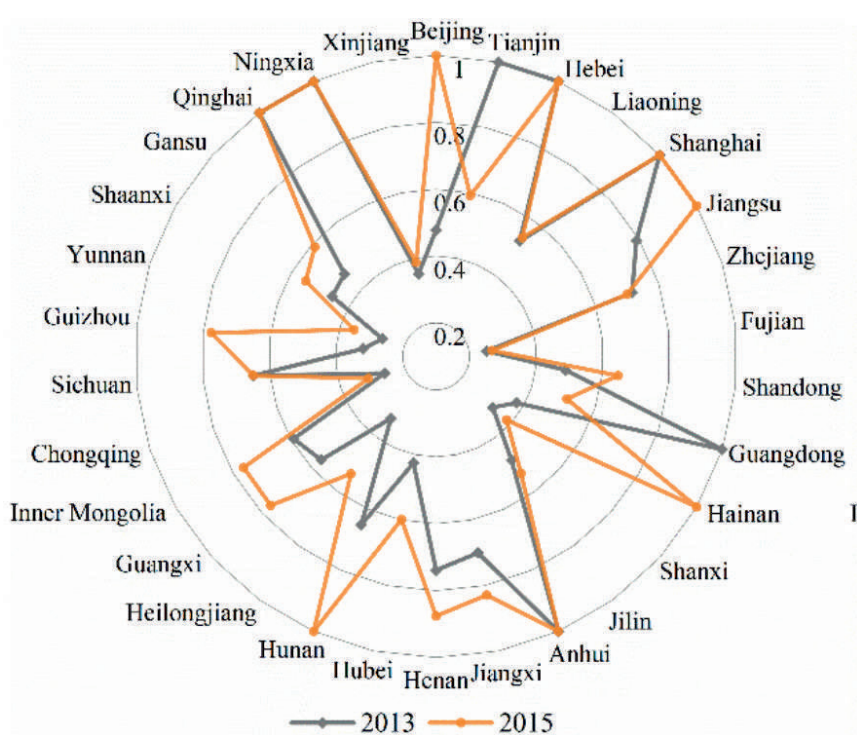

Fig. 3. The provincial energy efficiencies in 2013, 2015 and 2017.

low average EERT throughout 2013 to 2017. The energy efficiency in eastern area is higher than central area in 2013 and 2016, and lower than central area in 2014, 2015 and 2017.

As for the highway transportation, first, it can be seen that 4 provinces (Shanxi, Shanghai, Guangdong, Ningxia) are efficient during the research period. It's followed by Anhui and Hunan, which are efficient from 2013 to 2016, and 2014 to 2017, respectively. 7 provinces (Tianjin, Henan, Hunan, Guangxi, Sichuan, Guizhou, Qinghai) are efficient in three years, and Jiangsu is efficient in 2015 and 2016. Beijing, Shandong and Gansu are efficient in only one year. The values of energy efficiency in Chongqing is the lowest in 2013, 2015, 2016, 2017, and Yunnan performs worst in 2014, with great potential to enhance. Second, in the period of 2013 to 2017, the average EEHT is 0.545, 0.559, $0.756,0.712,0.705$, respectively. The efficiency value is relatively low, but it presents an apparent increasing trend in recent years. Third, based on Fig. 5b), it can be seen that the eastern area has the highest efficiency value from 2013 to 2017, and the efficiencies in three areas show a significant increasing trend from 2013 to 2017, except the efficiency in western area has a slight decline in 2016 and 2017.

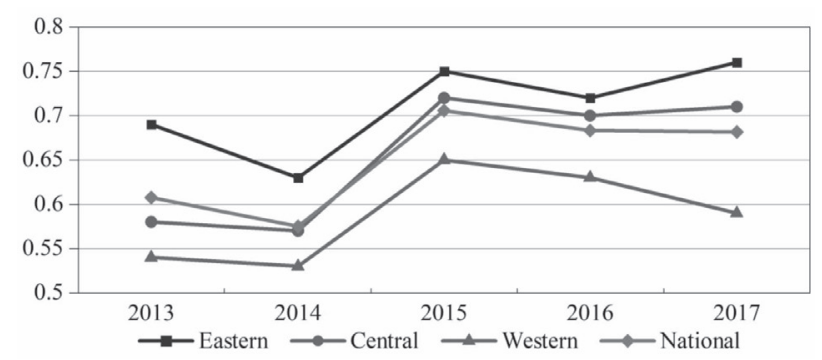

Fig. 4. The average energy efficiency of three areas from 2013 to 2017.

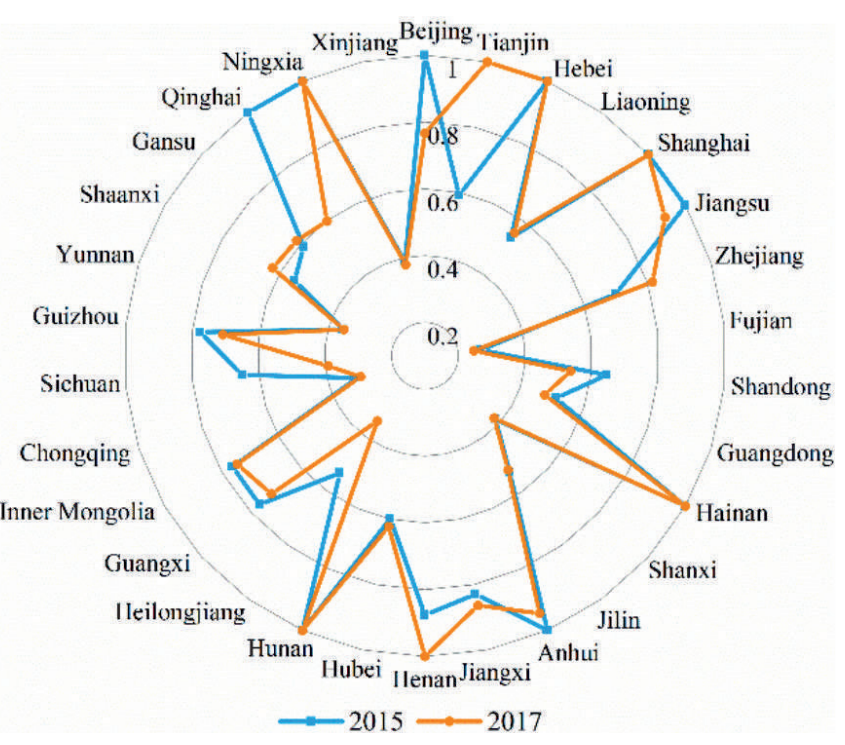

\section{Discussion and Policy Implications}

Discussion

After removing the effect of non-management factors, it can be found that the energy efficiencies of

a)

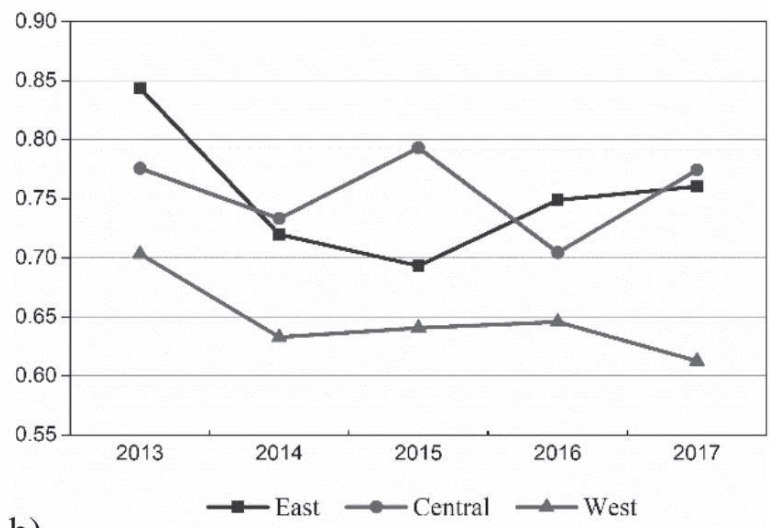

b)

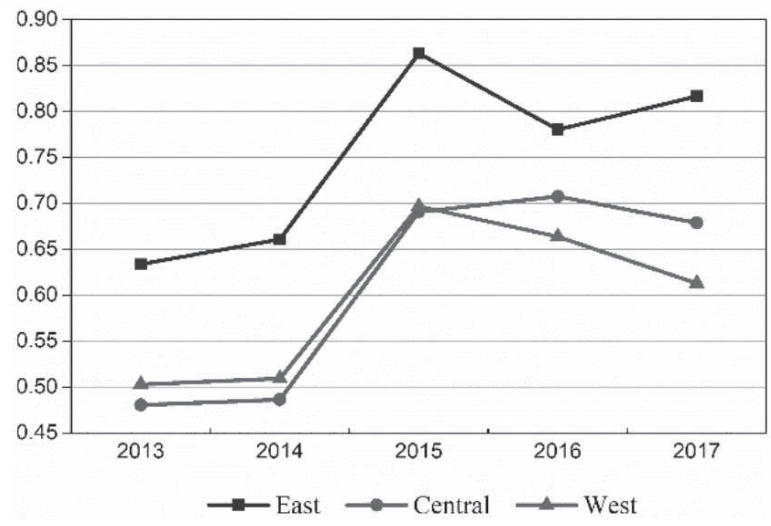

Fig. 5. The average energy efficiencies of three areas in railway and highway transportation. 
Table 7. The provincial EERT and EEHT from 2013 to 2017.

\begin{tabular}{|c|c|c|c|c|c|c|c|c|c|c|}
\hline \multirow{2}{*}{ Provinces } & \multicolumn{5}{|c|}{ EERT } & \multicolumn{5}{|c|}{ EEHT } \\
\hline & 2013 & 2014 & 2015 & 2016 & 2017 & 2013 & 2014 & 2015 & 2016 & 2017 \\
\hline Beijing & 1.000 & 1.000 & 1.000 & 1.000 & 1.000 & 0.284 & 0.320 & 1.000 & 0.346 & 0.581 \\
\hline Tianjin & 1.000 & 0.594 & 0.558 & 1.000 & 1.000 & 1.000 & 1.000 & 0.621 & 0.607 & 1.000 \\
\hline Hebei & 1.000 & 1.000 & 1.000 & 1.000 & 1.000 & 1.000 & 1.000 & 1.000 & 1.000 & 1.000 \\
\hline Shanxi & 0.382 & 0.308 & 0.378 & 0.369 & 0.347 & 0.295 & 0.267 & 0.389 & 0.401 & 0.415 \\
\hline Inner Mongolia & 1.000 & 1.000 & 1.000 & 1.000 & 1.000 & 0.393 & 0.386 & 0.597 & 0.620 & 0.583 \\
\hline Liaoning & 0.549 & 0.523 & 0.477 & 0.476 & 0.470 & 0.504 & 0.487 & 0.619 & 0.702 & 0.682 \\
\hline Jilin & 0.491 & 0.458 & 0.461 & 0.457 & 0.459 & 0.478 & 0.487 & 0.603 & 0.658 & 0.576 \\
\hline Heilongjiang & 0.698 & 0.669 & 1.000 & 0.565 & 0.635 & 0.237 & 0.226 & 0.345 & 0.340 & 0.261 \\
\hline Shanghai & 1.000 & 1.000 & 1.000 & 1.000 & 1.000 & 1.000 & 1.000 & 1.000 & 1.000 & 1.000 \\
\hline Jiangsu & 1.000 & 1.000 & 1.000 & 1.000 & 1.000 & 0.651 & 0.377 & 1.000 & 1.000 & 0.868 \\
\hline Zhejiang & 1.000 & 1.000 & 0.617 & 0.792 & 1.000 & 0.548 & 0.342 & 0.811 & 0.705 & 0.685 \\
\hline Anhui & 1.000 & 1.000 & 1.000 & 1.000 & 1.000 & 1.000 & 1.000 & 1.000 & 1.000 & 0.892 \\
\hline Fujian & 0.214 & 0.188 & 0.201 & 0.210 & 0.174 & 0.305 & 0.311 & 0.447 & 0.456 & 0.422 \\
\hline Jiangxi & 1.000 & 1.000 & 1.000 & 0.814 & 1.000 & 0.524 & 0.537 & 0.701 & 0.771 & 0.761 \\
\hline Shandong & 0.515 & 0.440 & 0.450 & 0.469 & 0.427 & 0.460 & 0.433 & 1.000 & 0.766 & 0.743 \\
\hline Henan & 1.000 & 0.734 & 0.758 & 0.668 & 1.000 & 0.530 & 0.588 & 1.000 & 1.000 & 1.000 \\
\hline Hubei & 0.635 & 0.695 & 0.748 & 0.762 & 0.753 & 0.311 & 0.319 & 0.487 & 0.492 & 0.525 \\
\hline Hunan & 1.000 & 1.000 & 1.000 & 1.000 & 1.000 & 0.470 & 0.467 & 1.000 & 1.000 & 1.000 \\
\hline Guangdong & 1.000 & 0.174 & 0.323 & 0.292 & 0.292 & 1.000 & 1.000 & 1.000 & 1.000 & 1.000 \\
\hline Guangxi & 0.578 & 0.528 & 0.590 & 0.619 & 0.513 & 0.549 & 0.537 & 1.000 & 1.000 & 1.000 \\
\hline Hainan & 1.000 & 1.000 & 1.000 & 1.000 & 1.000 & 0.218 & 1.000 & 1.000 & 1.000 & 1.000 \\
\hline Chongqing & 0.359 & 0.302 & 0.327 & 0.340 & 0.306 & 0.210 & 0.223 & 0.301 & 0.326 & 0.301 \\
\hline Sichuan & 0.462 & 0.454 & 0.463 & 0.448 & 0.394 & 1.000 & 1.000 & 1.000 & 0.530 & 0.389 \\
\hline Guizhou & 0.738 & 0.619 & 0.625 & 0.608 & 0.532 & 0.216 & 0.258 & 1.000 & 1.000 & 1.000 \\
\hline Yunnan & 0.343 & 0.323 & 0.363 & 0.324 & 0.346 & 0.215 & 0.202 & 0.352 & 0.389 & 0.367 \\
\hline Shaanxi & 0.578 & 0.513 & 0.564 & 0.569 & 0.529 & 0.394 & 0.416 & 0.540 & 0.652 & 0.772 \\
\hline Gansu & 1.000 & 0.717 & 0.701 & 0.678 & 0.608 & 0.295 & 0.329 & 0.512 & 1.000 & 0.624 \\
\hline Qinghai & 1.000 & 1.000 & 1.000 & 1.000 & 1.000 & 1.000 & 1.000 & 1.000 & 0.428 & 0.398 \\
\hline Ningxia & 1.000 & 1.000 & 1.000 & 1.000 & 1.000 & 1.000 & 1.000 & 1.000 & 1.000 & 1.000 \\
\hline Xinjiang & 0.678 & 0.504 & 0.415 & 0.517 & 0.511 & 0.258 & 0.252 & 0.362 & 0.354 & 0.310 \\
\hline Mean & 0.774 & 0.691 & 0.701 & 0.699 & 0.710 & 0.545 & 0.559 & 0.756 & 0.718 & 0.705 \\
\hline
\end{tabular}

19 provinces have decreased. And the average energy efficiency of the land transportation in the period of 2013 to 2017 decreases from 0.6863 considering non-management factors to 0.6507 excluding nonmanagement factors. Average efficiencies of the eastern area, central area, and western area during 2013 to 2017 respectively decreased $0.064,0.026$, and 0.014 , indicating that non-management factors resulted in the overestimation of provincial energy efficiency in
China's land transportation from 2013 to 2017. For provinces, with the non-management factors excluded, 7 provinces are efficient in 2017 (including Tianjin, Hebei, Shanghai, Hainan, Henan, Hunan, and Ningxia). Compared with the first stage, Beijing has left the efficiency frontier, indicating that the non-management factors of Beijing exert favorable effects on the energy efficiency of land transportation. Beijing and Tianjin decreased by 0.337 and 0.172 respectively, the biggest 
reductions in all provinces. The reason is that these two provinces get more support of the local governments, and formulate a sustainable development environment for industry [6], which is beneficial to the improvement of energy efficiency in the land transportation. In addition, considering that the efficiencies excluding the effect of non-management factors are more reliable, thus, the calculation results in the third stage will be adopted in subsequent discussions.

At the area level, the energy efficiencies show obvious area disparities in the land transportation. For highway transportation, the eastern area is the highest, followed by the central and western areas. The similar conclusion has been verified by Liu et al. [2], and this can be explained by two reasons. On the one hand, the eastern area has highly developed highway networks, and advanced technology and management systems [60], thus, the energy input is fully utilized and the energy loss in the production process has reduced which are conducive to the improvement of energy efficiency. On the other hand, the combustion efficiency of diesel is higher than that of gasoline, thus, from the perspective of energy consumption structure, a higher proportion of diesel use may promote the improvement of energy efficiency in the highway transportation [24]. And according to the raw data, the proportions of diesel usage in 2017 of the eastern, central, and western areas are 65\%, 66\% and 69\%, respectively. Thus, the eastern area has advantages in economy, technology and energy structure, which lead to higher energy efficiency. As for the railway transportation, the central and eastern areas all have a better performance. This means that the highway transportation in the central area exhibited a catch-up effect [64]. Note that the western area has the lowest energy efficiency not only in terms of the whole system, but also in every subsystem. The reason is that some manufacturing industries eliminated from eastern and central areas moved to the western area, which resulted in more transport service demand. Moreover, the energy efficiencies of three areas in terms of two subsystems are not high during the sample period. This finding means that there still exists huge potential for China's land transportation to improve the energy efficiency. The lower energy efficiency level results from the development limitations. In the early stages of development, backward technology and lack of energy saving awareness result in the poor performance in the land transportation. A series of energy saving policies have been formulated by the local governments, but the effects have not emerged for a long time due to the characteristics of the transport industries, i.e., intensive capitals and long circles [65].

At the regional level, Ningxia, Anhui, Hebei and Shanghai perform the best in the land transportation, which shows that they are also efficient in two subsystems. It can be found that there is no certain relationship between economic development level and energy efficiency. Take Ningxia and Anhui as examples, these two provinces are underdeveloped provinces, but they are efficient during the sample period. Structural factors may be the main reason for the high energy efficiency of Ningxia. The pillar industry in Ningxia is dominated by the primary industry, such as agriculture and animal husbandry, which can reduce the transport service demand and are beneficial to the improvement of the energy efficiency. For Anhui and Hebei, the reason may be that they have strong energy saving technology advantages in the transportation industry [65]. As for Shanghai, based on the traffic operation annual report of Shanghai in 2018, the number of metro vehicles has exceeded 5000, and average daily passenger flow is 9.69 million times, which further consolidates the dominant position of rail transit, thereby reducing the energy consumption of the land transportation. There are some provinces with low energy efficiency, such as Fujian (0.2580), Shanxi (0.3521), Heilongjiang (0.3836), Chongqing (0.2934), Yunnan (0.3155), and Xinjiang (0.3692). Take Fujian as an example, the raw data indicates that the average passenger turnover volume and the average freight turnover volume from 2013 to 2017 in Fujian are $23.08 \%$ and $59.59 \%$ less than the national average value respectively, which indicates that Fujian should further improve the management level to increase energy efficiency. All of these provinces are located in the central and western areas except for Fujian. This result means that although no certain relations are found in economic level and energy efficiency, the central and western areas still deserve more attention. Moreover, seven provinces (including Beijing, Jiangsu, Hainan, Hunan, Qinghai and Inner Mongolia) are efficient in the railway transportation from 2013 to 2017, but inefficient in the highway transportation, which lead to the energy inefficient of the whole land transportation. Guangdong is efficient in the highway transportation, but inefficient in the railway transportation. The findings reveal the efficiency difference between these two subsystems of the land transportation. Take Beijing as an example, traffic jam problem in Beijing's highway transportation is particularly acute in recent years, which exacerbates the difficulty of management in the transportation. And the traffic jams always lead to frequent braking and acceleration, which will increase the energy consumption [66]. These results show that only the two subsystems are efficient, can the whole land transportation system be efficient, therefore, both railway and highway transportation should get the attention of the local governments.

In addition, as shown in Table 7, the average efficiencies of railway transportation during the sample period are $0.774,0.691,0.701,0.699$, and 0.710 respectively, while that of highway transportation are $0.545,0.559,0.756,0.718$, and 0.705 respectively. The EERT is apparently better than EEHT in 2013 and 2014, however, the EEHT is slightly higher than EERT in next two years. It can be inferred that the inefficiency of the land transportation mainly derives from the lower 
performance of the highway transportation from 2013 to 2014. And the efficiency disparities between these two subsystems has narrowed in next three years, indicating the influence of the highway transportation in the whole land transportation system is increasing.

To illustrate the changing trend of energy efficiencies in two subsystems over time and further analyzes the efficiency difference between railway and highway transportation from 2013 to 2017. Fig. 6 is plotted with the sequence of graphs corresponding to the time. 30 provinces can be grouped into four categories according to the average values of EERT and EEHT, namely, high-high group, low-high group, low-low group, and high-low group. Fig. 6 shows that EEHT presented an increasing trend, it can be found that most provinces have a low EEHT in 2013 and 2014, then the numbers of provinces with high EEHT have a sharp increase in 2015, and keep relatively steady from 2015 a)

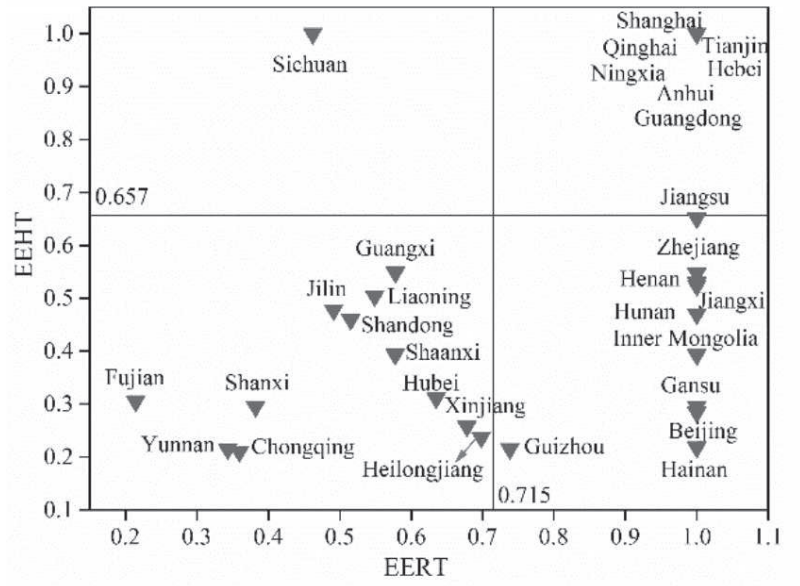

c)

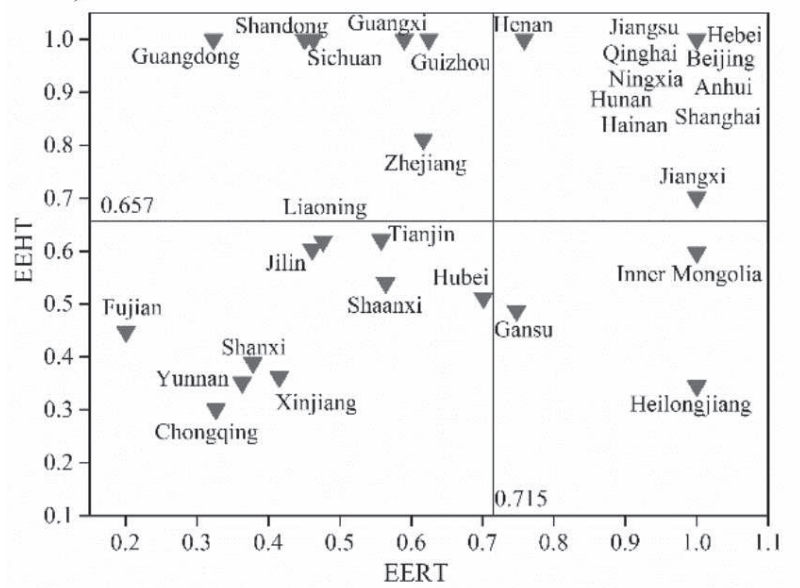

b)

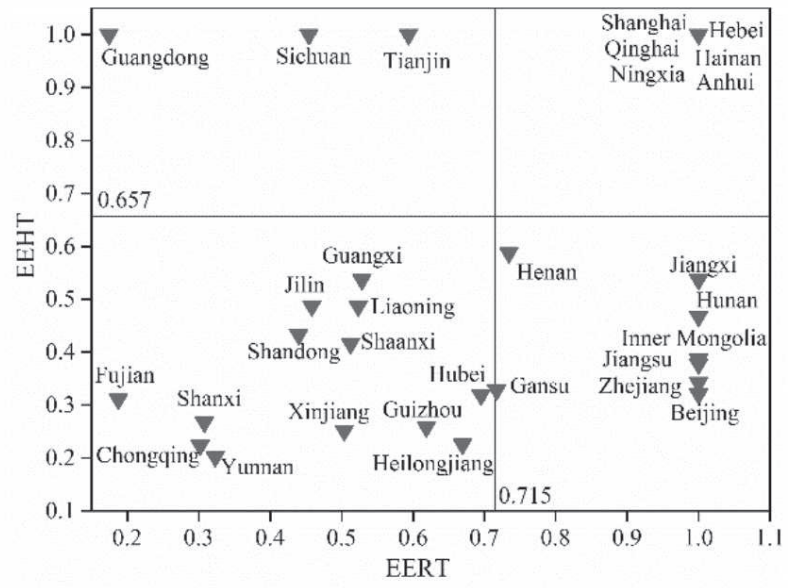

d)

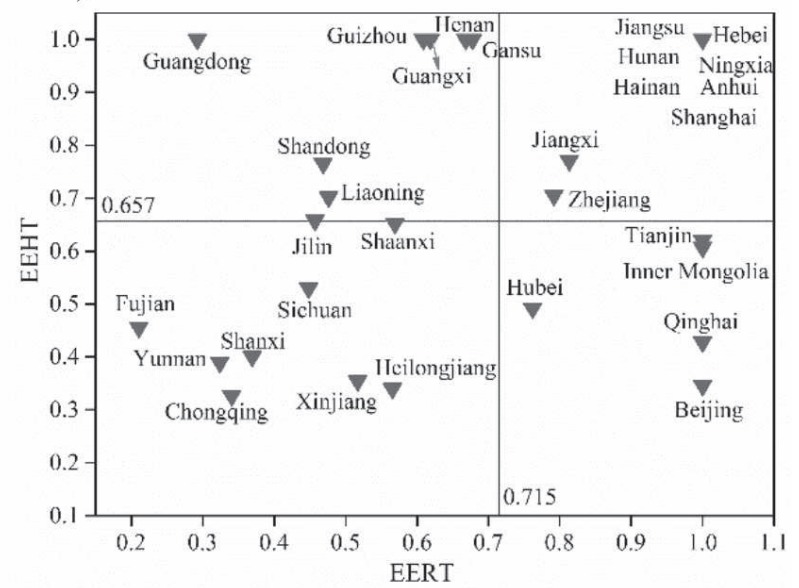

e)

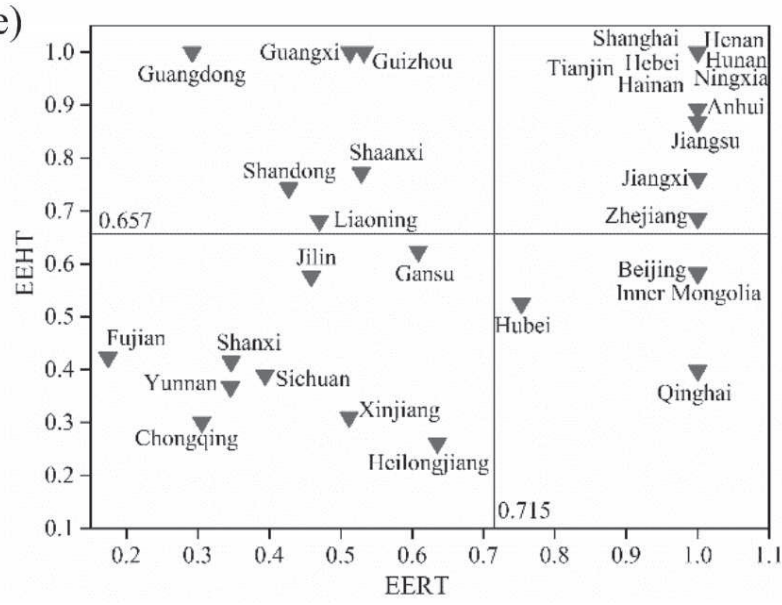

Fig. 6. The provincial EERT and EEHT from 2013 to 2017. 


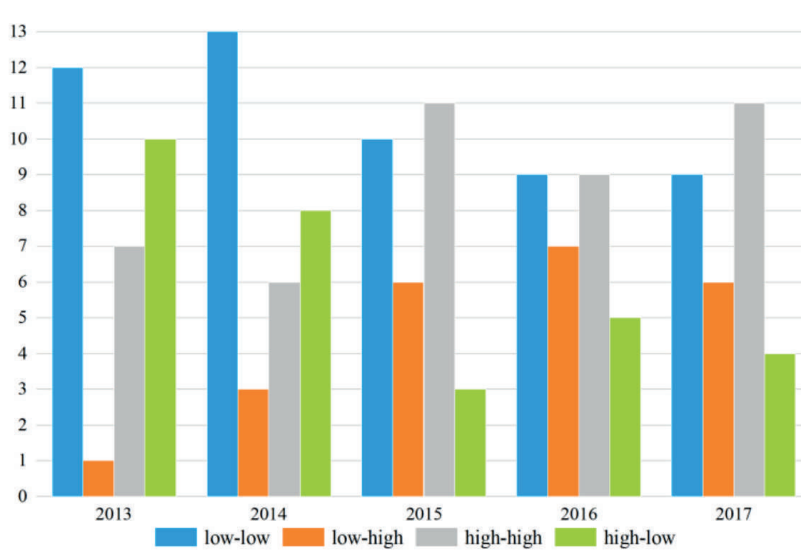

Fig. 7. The numbers of different groups from 2013 to 2017.

to 2017, the proportion of provinces with high EEHT exceeded 50\% from 2015 to 2017, indicating that the administrative level in China's highway transportation have improved greatly within the study period. Different from the trends in EEHT, the proportion of provinces with high EERT accounted for nearly $50 \%$ in each year between 2013 and 2017, showing that no significant changes happened in the railway transportation as a whole.

Fig. 7 presents the changes in the number of provinces within the four groups over time. It can be found that the numbers of provinces in high-low and low-low group show a decreasing trend from 2013 to 2017, while having an increasing trend in low-high and high-high groups. Specifically, 4 provinces (Shanghai, Hebei, Anhui, Ningxia and Hainan) have been in highhigh group, except Hainan in 2013. These provinces can be the benchmark for other provinces as they have both high EERT and EEHT. On the contrary, 8 provinces (Fujian, Yunnan, Chongqing, Xinjiang, Shanxi, Jilin, Heilongjiang, Shaanxi) are in low-low group, except Heilongjiang in 2015 and Shaanxi in 2017, indicating that these provinces have great potential to enhance the EERT and EEHT. Inner Mongolia has always been in high-low group, which indicates that it should improve the managerial level in highway transportation to increase the EEHT. Table 8 demonstrates the variation of the remaining 16 provinces between the four groups from 2013 to 2017. 1, 2, 3, 4 respectively represent quadrant I, II, III and IV. It shows that 5 provinces (Jiangsu, Jiangxi, Hunan, Zhejiang, Henan) have a better change trend, since Jiangsu, Jiangxi, Hunan and Henan change from high-low group to highhigh group in 2015 and remain steady in next three years, except Henan in 2016, Zhejiang arrived highhigh group in 2016. 4 provinces (Hubei, Shandong, Liaoning, Guangxi) don not reach the high-high group, but their overall efficiency change trend is developing in a better direction. In detail, Shandong, Liaoning and Guangxi change from quadrant III to quadrant II, which shows that these provinces have increased EEHT during the research time, but still have a bad performance in EERT, so some measures in railway transportation should be taken to arrive highhigh group for these provinces. Hubei changes from quadrant III to quadrant IV in 2016, meaning EEHT should be increased. 4 provinces (Guangdong, Qinghai, Sichuan and Gansu) presented bad change trends within 5 years. Specifically, Guangdong left the high-high group in 2014 and were in low-high group within next four years, Qinghai dropped the high-high group from 2016, these two provinces should improve EERT and EEHT, respectively, Sichuan and Gansu reached lowlow group in 2016 and 2017, respectively, which means both EERT and EEHT should be improved for these two provinces. In addition, Guizhou went from highlow to low-low to low-high group, indicating EERT in Guizhou should be increased.

\section{Policy Implications}

To improve the energy efficiency of the land transportation system, several policy suggestions are proposed based on the above results and discussion.

(1) The policy decision-makers should refer to the efficiency evaluation results with excluding the nonmanagement factors, since traditional SBM model cannot eliminate the effects of non-management factors, which may make the evaluated results

Table 8. The variation of 16 provinces between the four groups from 2013 to 2017 .

\begin{tabular}{|c|c|c|c|c|c|c|c|c|c|c|c|}
\hline Provinces & 2013 & 2014 & 2015 & 2016 & 2017 & Provinces & 2013 & 2014 & 2015 & 2016 & 2017 \\
\hline Jiangsu & 4 & 4 & 1 & 1 & 1 & Guangxi & 3 & 3 & 2 & 2 & 2 \\
\hline Jiangxi & 4 & 4 & 1 & 1 & 1 & Guangdong & 1 & 2 & 2 & 2 & 2 \\
\hline Hunan & 4 & 4 & 1 & 1 & 1 & Qinghai & 1 & 1 & 1 & 4 & 4 \\
\hline Zhejiang & 4 & 4 & 2 & 1 & 1 & Sichuan & 2 & 2 & 2 & 3 & 3 \\
\hline Henan & 4 & 4 & 1 & 2 & 1 & Gansu & 4 & 4 & 4 & 2 & 3 \\
\hline Hubei & 3 & 3 & 3 & 4 & 4 & Guizhou & 4 & 3 & 2 & 2 & 2 \\
\hline Shandong & 3 & 3 & 2 & 2 & 2 & Tianjin & 1 & 2 & 3 & 4 & 1 \\
\hline Liaoning & 3 & 3 & 3 & 2 & 2 & Beijing & 4 & 4 & 1 & 4 & 4 \\
\hline
\end{tabular}


distorted. Industrial structure exerts a negative effect on the energy efficiency, so local governments should accelerate the industrial structure adjustments to switch from the development mode relying on massive energy inputs to modern industries which are lowenergy-consumption and high value added. Moreover, according to the SFA regression results, excessive investments may lead to the unreasonable allocation of resources, which will result in resource redundancy and hinder the improvement of energy efficiency, Thus, the local government should consider the reasonable allocation of funds in land transportation sector.

(2) Energy efficiencies in the land transportation present significant area disparities, how to narrow the area imbalances of the land transportation should be concerned. We suggest that both the railway and highway transportations should pay more attention to the western area owing to its bad performance in recent years. On the one hand, the western area can strengthen the technical cooperation with the central and eastern areas, because technical transfer is more convenient to establish traffic system and promote energy conservation for the western area [9], on the other hand, several provinces in the western area, such as Xinjiang and Inner Mongolia who are rich in renewable energy, can develop clean energy strategies to improve the energy efficiency. Moreover, the eastern and central areas have better economic development level, thus, it's more suitable for these two areas to increase investment in infrastructure construction, such as the electric vehicle charging pile.

(3) Different policies should be formulated concerning four different groups. Specifically, for the provinces categorized to the low-low group, such as Fujian, Yunnan, Chongqing, Xinjiang, Shanxi, Jilin and Heilongjiang, both EERT and EEHT should be boosted to guarantee the improvement of energy efficiency in land transportation; the provinces attributed to the lowhigh group, such as Guangdong and Shandong in recent three years, shall continue to increase the proportion of electric locomotive in the railway sector, which is conducive to reducing fuel energy consumption and improving the EERT; the provinces attributed to highlow group, such as Hubei and Beijing in 2016, 2017, shall expand the market share of electric vehicles and public transport, so that the numbers of private cars relying on gasoline can decrease greatly, which is beneficial to the improvement of energy efficiency in the highway transportation.

\section{Conclusions}

The aim of this article is to analyze the energy efficiency of China's provincial land transportation (including railway and highway transportation). A parallel structure of land transportation is firstly constructed. Then, the parallel SBM model and three stage of DEA approach are combined to measure the energy efficiency at provincial level from 2013 to 2017 with excluding the impacts of non-management factors. And, the energy efficiencies in railway and highway transportation are also calculated by means of efficiency decomposition approach. Through the empirical energy efficiency evaluation of China's 30 administrative provinces, several primary conclusions can be obtained as follows:

(1) Non-management factors (including per capita GDP, industrial structure and statistical noise in this paper) do exert unfavorable influences on the energy efficiency measurement of China's land transportation. Generally, the non-management factors do result in the overestimation of energy efficiencies.

(2) The energy efficiencies of China's land transportation present significant area differentiation. The eastern area is the highest, followed by the central and western areas. For railway transportation, the western area still performs worst, the central and eastern areas fluctuated obviously. In terms of highway transportation, the eastern area has the highest efficiency value, while the central and western areas have a poor performance.

(3) The average energy efficiency of China's land transportation is low, with a huge potential to improve. From the dynamic perspective, the energy efficiencies of the whole land transportation and the highway transportation present a significant upward trend during the sample period. However, the changing trend is not promising for the railway transportation.

(4) The inefficiency of the land transportation mainly derives from the lower performance of the highway transportation from 2013 to 2014, however, the influence of the highway transportation in the whole land transportation system is increasing in next three years.

\section{Acknowledgements}

This work was supported by the National Social Sciences Foundation of China under Grant No.14BXW026.

\section{Conflict of Interest}

The authors declare no conflict of interest.

\section{References}

1. CUI Q., LI Y. The evaluation of transportation energy efficiency: An application of three-stage virtual frontier DEA. Transportation Research Part D: Transport and Environment, 29, 1, 2014.

2. LIU H.W., ZHANG Y., ZHU Q.Y., CHU J.F. Environmental efficiency of land transportation in China: A parallel slackbased measure for regional and temporal analysis. Journal of Cleaner Production, 142, 867, 2017. 
3. CHUNG W., ZHOU G.H., YEUNG I.M.H. A study of energy efficiency of transport sector in China from 2003 to 2009. Applied Energy, 112, 1066, 2013.

4. ZHA Y., ZHAO L.L., BIAN Y.W. Measuring regional efficiency of energy and carbon dioxide emissions in China: A chance constrained DEA approach. Computers \& Operations Research, 66, 2016.

5. TAN B., YAVUZ Y., OTAY E.N., ÇAMLIBEL E. Optimal selection of energy efficiency measures for energy sustainability of existing buildings. Computers \& Operations Research, 66, 258, 2016.

6. ZHAO H.R., GUO S., ZHAO H.R. Provincial energy efficiency of China quantified by three-stage data envelopment analysis. Energy, 166, 96, 2019.

7. HU J.L., WANG S.C. Total-factor energy efficiency of regions in China. Energy Policy, 34 (17), 3206, 2006.

8. LIN B.Q., WANG X.L. Exploring energy efficiency in China's iron and steel industry: A stochastic frontier approach. Energy Policy, 72, 87, 2014.

9. XIE C.P., BAI M.Q., WANG X.L. Accessing provincial energy efficiencies in China's transport sector. Energy Policy, 123, 525, 2018.

10. CHARNES A., COOPER W.W., RHODES E. Measuring the efficiency of decision making units. European Journal of Operational Research, 2 (6), 1978.

11. CHEN X.H., GAO Y.Y., AN Q.X., WANG Z.R., NERALIĆ L. Energy efficiency measurement of Chinese Yangtze River Delta's cities transportation: A DEA window analysis approach. Energy Efficiency, 11 (8), 1941, 2018.

12. FIALLOS J., PATRICK J., MICHALOWSKI W., FARION K. Using data envelopment analysis for assessing the performance of pediatric emergency department physicians. Health Care Management Science, 20 (1), 2017.

13. ZARE H., TAVANA M., MARDANI A., MASOUDIAN S., KAMALI SARAJI M. A hybrid data envelopment analysis and game theory model for performance measurement in healthcare. Health Care Management Science, 22 (3), 2019.

14. HU P., CHEN N., LI Y.J., XIE Q.W. Efficiency evaluation of water consumption in a Chinese province-level region based on data envelopment analysis. Water, 10 (6), 2018.

15. ZHOU X.Y., XU Z.W., YAO L.M., TU Y., LEV B., PEDRYCZ W. A novel Data Envelopment Analysis model for evaluating industrial production and environmental management system. Journal of Cleaner Production, 170, 773, 2018.

16. JIANG H.C., HE Y.F. Applying data envelopment analysis in measuring the efficiency of Chinese listed banks in the context of macroprudential framework. Mathematics, 6 (10), 2018.

17. LOZANO S. Slacks-based inefficiency approach for general networks with bad outputs: An application to the banking sector. Omega, 60, 73, 2016.

18. WANG J.M., SHI Y.F., ZHANG J. Energy efficiency and influencing factors analysis on Beijing industrial sectors. Journal of Cleaner Production, 167, 653, 2017.

19. BOROZAN D. Technical and total factor energy efficiency of European regions: A two-stage approach. Energy, 152, 521, 2018.

20. YANG Z.S., WEI X.X. The measurement and influences of China's urban total factor energy efficiency under environmental pollution: Based on the game crossefficiency DEA. Journal of Cleaner Production, 209, 439, 2019.
21. BI G.B., WANG P.C., YANG F., LIANG L. Energy and environmental efficiency of China's transportation sector: A multidirectional analysis approach. Mathematical Problems in Engineering, 2014 (6), 1, 2014.

22. ZHANG N., CHOI Y. A note on the evolution of directional distance function and its development in energy and environmental studies 1997-2013. Renewable and Sustainable Energy Reviews, 33, 50, 2014.

23. SONG M.L., ZHENG W.P., WANG Z.Y. Environmental efficiency and energy consumption of highway transportation systems in China. International Journal of Production Economics, 181, 441, 2016.

24. LIU Z., QIN C.X., ZHANG Y.J. The energy-environment efficiency of road and railway sectors in China: Evidence from the provincial level. Ecological Indicators, 69, 559, 2016.

25. YANG T., CHEN W., ZHOU K.L., REN M.L. Regional energy efficiency evaluation in China: A super efficiency slack-based measure model with undesirable outputs. Journal of Cleaner Production, 198, 859, 2018.

26. LIU X., LIU J. Measurement of low carbon economy efficiency with a three-stage data envelopment analysis: A comparison of the largest twenty $\mathrm{CO}_{2}$ emitting countries. Int J Environ Res Public Health, 13 (11), 2016.

27. ZHOU Y., KONG Y., ZHANG T. The spatial and temporal evolution of provincial eco-efficiency in China based on SBM modified three-stage data envelopment analysis. Environmental Science Pollution Ressearch, 27 (8), 2020.

28. FRIED H.O., LOVELL C.A.K., SCHMIDT S.S., YAISAWARNG S. Accounting for environmental effects and statistical noise in data envelopment analysis. Journal of Productivity Analysis, 17 (1), 2002.

29. CHEN Y., LIU B.S., SHEN Y.H., WANG X.Q. The energy efficiency of China's regional construction industry based on the three-stage DEA model and the DEA-DA model. KSCE Journal of Civil Engineering, 20 (1), 34, 2015.

30. WANG Z.H., SUN Y.F., YUAN Z.Y., WANG B. Does energy efficiency have a spatial spill-over effect in China? Evidence from provincial-level data. Journal of Cleaner Production, 241, 2019.

31. KAO C., HWANG S.N. Efficiency measurement for network systems: IT impact on firm performance. Decision Support Systems, 48 (3), 437, 2010.

32. FÄRE R., GROSSKOPF S. Network DEA. SocioEconomic Planning Sciences 34 (1), 2000.

33. COOK W.D., LIANG L., ZHU J. Measuring performance of two-stage network structures by DEA: A review and future perspective. Omega, 38 (6), 423, 2010.

34. TONE K., TSUTSUI M. Dynamic DEA: A slacks-based measure approach. Omega, 38 (3-4), 145, 2010.

35. KAO C. Efficiency decomposition for parallel production systems. Journal of the Operational Research Society, 63 (1), 64, 2012.

36. DU J., ZHU J., COOK W.D., HUO J. DEA models for parallel systems: Game-theoretic approaches. Asia-Pacific Journal of Operational Research, 32 (02), 2015.

37. KAO C., HWANG S.N. Efficiency decomposition in twostage data envelopment analysis: An application to nonlife insurance companies in Taiwan. European Journal of Operational Research, 185 (1), 418, 2008.

38. CHEN Y., COOK W.D., LI N., ZHU J. Additive efficiency decomposition in two-stage DEA. European Journal of Operational Research, 196 (3), 1170, 2009.

39. LI D., WANG M.Q., LEE C. The waste treatment and recycling efficiency of industrial waste processing 
based on two-stage data envelopment analysis with undesirable inputs. Journal of Cleaner Production, 242, 2020.

40. ZHOU X.Y., LUO R., YAO L.M., CAO S., WANG S.Y., LEV B. Assessing integrated water use and wastewater treatment systems in China: A mixed network structure two-stage SBM DEA model. Journal of Cleaner Production, 185, 533, 2018.

41. SHAO L.G., YU X., FENG C. Evaluating the ecoefficiency of China's industrial sectors: A twostage network data envelopment analysis. Journal of Environmental Management, 247, 551, 2019.

42. WU J., ZHU Q.Y., CHU J.F., LIU H.W., LIANG L. Measuring energy and environmental efficiency of transportation systems in China based on a parallel DEA approach. Transportation Research Part D: Transport and Environment, 48, 460, 2016.

43. LEI X.Y., LI L., ZHANG X.F., DAI Q.Z., FU Y.L. A novel ratio-based parallel DEA approach for evaluating the energy and environmental performance of Chinese transportation sectors. Journal of Systems Science and Systems Engineering, 28 (5), 621, 2019.

44. XU X., CUI Q. Evaluating airline energy efficiency: An integrated approach with network epsilon-based measure and network slacks-based measure. Energy, 122, 274, 2017.

45. MA J.F., CHEN L. Evaluating operation and coordination efficiencies of parallel-series two-stage system: A data envelopment analysis approach. Expert Systems with Applications, 91, 1, 2018.

46. AN Q.X., WANG Z.R., EMROUZNEJAD A., ZHU Q.Y., CHEN X.H. Efficiency evaluation of parallel interdependent processes systems: An application to Chinese 985 project universities. International Journal of Production Research, 57 (17), 5387, 2018.

47. KAO C. Efficiency decomposition and aggregation in network data envelopment analysis. European Journal of Operational Research, 255 (3), 778, 2016.

48. KAO C. Efficiency decomposition in network data envelopment analysis with slacks-based measures. Omega, 45, $1,2014$.

49. TANG J.X., WANG Q.W., CHANG Y.T. China's regional industrial two-stage system - Efficiencies and their influencing factors. Journal of Cleaner Production, 249, 2020.

50. WU J., WANG C., ZHOU Z.X. Industrial pollutant treatment efficiency considering environmental factors. Journal of Modelling in Management, 14 (3), 773, 2019.

51. KAO C. Decomposition of slacks-based efficiency measures in network data envelopment analysis. European Journal of Operational Research, 283 (2), 588, 2020.

52. KAO C. Network data envelopment analysis: A review. European Journal of Operational Research, 239 (1), 1, 2014.
53. HERRERA-RESTREPO O., TRIANTIS K., TRAINOR J., MURRAY-TUITE P., EDARA P. A multi-perspective dynamic network performance efficiency measurement of an evacuation: A dynamic network-DEA approach. Omega, 60, 45, 2016.

54. YU J.Q., ZHOU K.L., YANG S.L. Regional heterogeneity of China's energy efficiency in "new normal": A metafrontier Super-SBM analysis. Energy Policy, 134, 110941, 2019.

55. KAO C. Inefficiency identification for closed series production systems. European Journal of Operational Research, 275 (2), 599, 2019.

56. FENG C., WANG M. Analysis of energy efficiency in China's transportation sector. Renewable and Sustainable Energy Reviews, 94, 565, 2018.

57. MA F., WANG W.L., SUN Q.P., LIU F., LI X.D. Integrated transport efficiency and its spatial convergence in China's provinces: A super-SBM DEA Model considering undesirable outputs. Applied Sciences, 8 (9), 2018.

58. LIU H.W., WU J., CHU J.F. Environmental efficiency and technological progress of transportation industry-based on large scale data. Technological Forecasting and Social Change, 144, 475, 2019.

59. STEFANIEC A., HOSSEINI K., XIE J.H., LI Y.J. Sustainability assessment of inland transportation in China: A triple bottom line-based network DEA approach. Transportation Research Part D: Transport and Environment, 80, 2020.

60. LIU W.S., LIN B.Q. Analysis of energy efficiency and its influencing factors in China's transport sector. Journal of Cleaner Production, 170, 674, 2018.

61. LIU Q.Z., LUO C. The impact of government integrity on investment efficiency in regional transportation infrastructure in China. Sustainability, 11 (23), 2019.

62. TANG T.B., YOU J.X., SUN H., ZHANG H. Transportation efficiency evaluation considering the environmental impact for China's freight sector: A parallel data envelopment analysis. Sustainability, 11 (18), 2019.

63. YIN J.Y., CAO Y.F., TANG B.J. Fairness of China's provincial energy environment efficiency evaluation: Empirical analysis using a three-stage data envelopment analysis model. Natural Hazards, 95 (1-2), 343, 2018.

64. LIU H.W., YANG R.L., WANG Y.Q., ZHU Q.Y. Measuring performance of road transportation industry in China in terms of integrated environmental efficiency in view of streaming data. Science of The Total Environment, 727, 138675, 2020.

65. ZHANG Y.J., JIANG L., SHI W. Exploring the growthadjusted energy-emission efficiency of transportation industry in China. Energy Economics, 90, 104873, 2020.

66. LI Y., UKKUSURI S.V., FAN J. Managing congestion and emissions in transportation networks with dynamic carbon credit charge scheme. Computers \& Operations Research, 99, 90, 2018. 